\title{
ZBP-89 function in colonic stem cells and during butyrate-
} induced senescence

\author{
Ramon Ocadiz-Ruiz ${ }^{1}$, Amanda L. Photenhauer ${ }^{1}$, Michael M. Hayes $^{1}$, Lin Ding ${ }^{1}$, Eric \\ R. Fearon ${ }^{2}$ and Juanita L. Merchant ${ }^{1,3}$ \\ ${ }^{1}$ Department of Internal Medicine, Division of Gastroenterology, University of Michigan, Ann Arbor, MI, USA \\ ${ }^{2}$ Division of Molecular Medicine, University of Michigan, Ann Arbor, MI, USA \\ ${ }^{3}$ Department of Molecular and Integrative Physiology, University of Michigan, Ann Arbor, MI, USA \\ Correspondence to: Juanita L. Merchant, email: merchanj@umich.edu \\ Keywords: organoids, Apc, CDKN2A, ChIP-Seq, SA-bGal \\ Abbreviations: SCFA = short chain fatty acids, $t d T=t d T o m a t o, T x=$ tamoxifen, HDAC = histone deacetylase \\ Received: August 02, $2017 \quad$ Accepted: September 08, $2017 \quad$ Published: October 09, 2017 \\ Copyright: Ocadiz-Ruiz et al. This is an open-access article distributed under the terms of the Creative Commons Attribution \\ License 3.0 (CC BY 3.0), which permits unrestricted use, distribution, and reproduction in any medium, provided the original author \\ and source are credited.
}

\section{ABSTRACT}

ZBP-89 (Zfp148, ZNF148) is a Kruppel-type zinc-finger family transcription factor that binds to GC-rich DNA elements. Earlier studies in cell lines demonstrated that ZBP89 cooperates with Wnt $\beta$-catenin signaling by inducing $\beta$-catenin gene expression. Since $\beta$-catenin levels are normally highest at the crypt base, we examined whether ZBP-89 is required for stem cell maintenance. Lineage-tracing using a Zfp148Cre ${ }^{E R T 2}$ transgenic line demonstrated expression in both intestine and colonic stem cells. Deleting the Zfp148 locus in the colon using the Cdx2NLSCre ${ }^{E R T 2}$ transgene, reduced the size and number of polyps formed in the Apc-deleted mice. Since colon polyps form in the presence of butyrate, a short chain fatty acid that suppresses cell growth, we examined the direct effect of butyrate on colon organoid survival. Butyrate induced senescence of colon organoids carrying the Apc deletion, only when Zfp148 was deleted. Using quantitative PCR and chromatin immunoprecipitation, we determined that butyrate treatment of colon cell lines suppressed ZNF148 gene expression, inducing CDKN2a ( 16 $^{\text {Ink4a }}$ ) gene expression. Collectively, Zfp148 mRNA is expressed in CBCs, and is required for stem cell maintenance and colonic transformation. Butyrate induces colonic cell senescence in part through suppression of ZBP-89 gene expression and its subsequent occupancy of the CDKN2A promoter.

\section{INTRODUCTION}

Zinc Finger Binding Protein-89 kDa (ZBP-89, human ZNF148 or mouse Zfp148 loci) is a ubiquitously expressed Krüppel-type zinc finger transcription factor that binds GC-rich DNA elements $[1,2]$. We previously showed that histone deacetylase inhibition (HDACi), e.g., with butyrate or trichostatin A (TSA) contributes to ZBP-89 induction of CDKN1B ( $p 21^{\text {Wafl }}$ ) and its proteinprotein interaction with tumor suppressor proteins $\mathrm{p} 53$, ataxia telangiectasia mutated (ATM), and p300, a histone acetyltransferase (HAT) [2-4]. In addition, ZBP-89 mediates transcriptional repression of the vimentin and
CDKN2A ( $16^{I N K 44}$ ) genes by recruiting HDACs to their promoters [5-7]. ZBP-89 induces tryptophan hydroxylase (Tph1) by synergizing with $\beta$-catenin, and contributes to the mucosal defense against $S$. typhimurium [8]. Having established that ZBP-89 and $\beta$-catenin cooperate in normal colonic mucosal restitution, we tested and found that ZBP89 contributes to intestinal polyp formation initiated by deletion of the Apc locus [9].

Conditional deletion of the Zfp148 locus in intestinal epithelial cells reduced the expected number of small intestinal polyps in a mouse model of deleted $A p c$, demonstrating that ZBP-89 is required for $\beta$-catenindependent polyp formation [9]. We found that $\beta$-catenin 
binds to the ZNF148 promoter stimulating ZBP-89 gene expression. Similarly, ZBP-89 protein binds to the CTNNB1 ( $\beta$-catenin) promoter inducing $\beta$-catenin transcription. In this way, ZBP-89 contributes to a feedforward gene expression loop that can maintain elevated levels of $\beta$-catenin when and where Wnt signaling is high [9], such as in the normal stem cell niche and in colon cancer. Accordingly, we also showed that ZBP-89 expression correlates with poor survival after surgical resection for colorectal cancer and that ZBP-89 protein expression is elevated in colorectal cancer (CRC) [9].

In both the intestine and colon, Wnt signaling is highest at the base of the glands or crypts suggesting that ZBP-89 might play an essential role in the stem cell niche. To test this hypothesis directly, we studied the expression and function of ZBP-89 in intestinal and colonic stem cells and found that the transcription factor is expressed in the crypt basal columnar cells (CBCs) that eventually differentiate and repopulate the small intestine and colon glands. Moreover, ZBP-89 is also required for polyp growth in the colon of

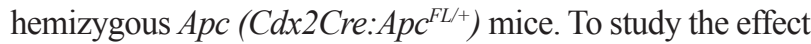
of a common bacterial metabolite on stem cell maintenance, colonic organoids generated from wild type (WT) and
Cdx2Cre: $A p c^{\mathrm{FL} /+}$ mouse colons were cultured in the presence of the short-chain fatty acid (SCFA) butyrate. We found that organoids generated from the $C d x 2 C r e: A p c^{F L /+}$ colon retain their stem cell phenotype in the presence of butyrate. However, deleting Zfp148 decreased colonic organoid growth and allowed the organoids to senesce. Collectively, our results demonstrate that ZBP-89 plays a role in stem cell differentiation during homeostasis and transformation through its ability to suppress senescence.

\section{RESULTS}

\section{ZBP-89 protein is highly expressed in CBCs and transit-amplifying (TA) cells}

To determine the mucosal location of ZBP-89 protein expression in the luminal gastrointestinal tract, we performed immunohistochemistry (IHC) on tissue from the small intestine (duodenum, jejunum and ileum) and colon (proximal and distal colon). In the small intestine, ZBP-89 protein was expressed primarily in the transit-amplifying (TA) cells and in scattered cells at the crypt base (Figure 1A). Expression diminished at the villus tip, where senescent cells slough into the lumen. In the
A

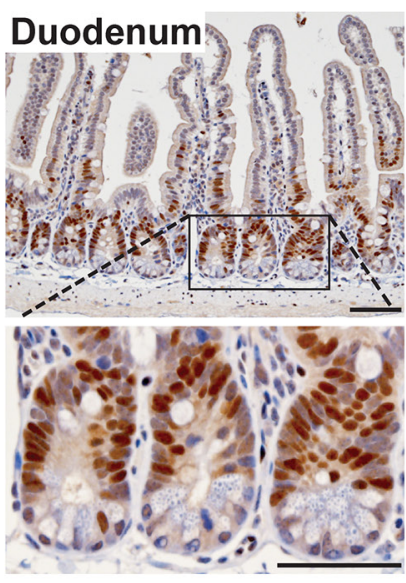

B

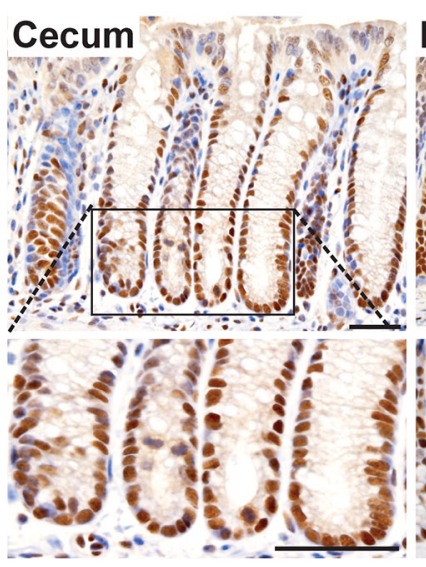

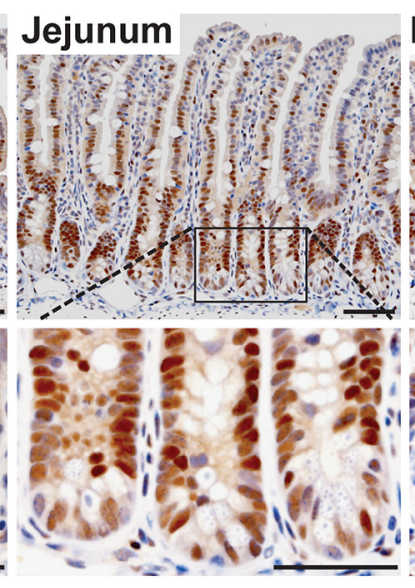

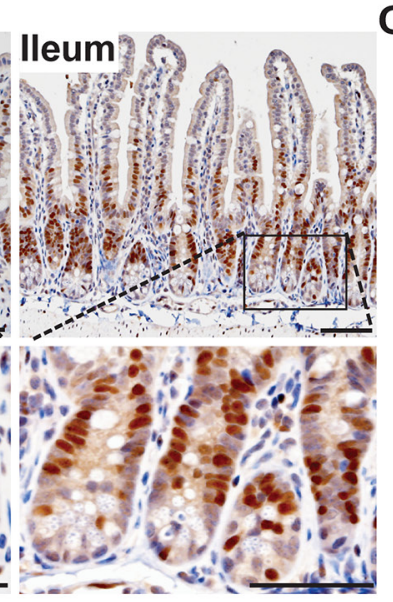

Prox. colon if dis

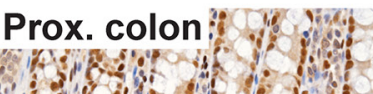

Dist. colon

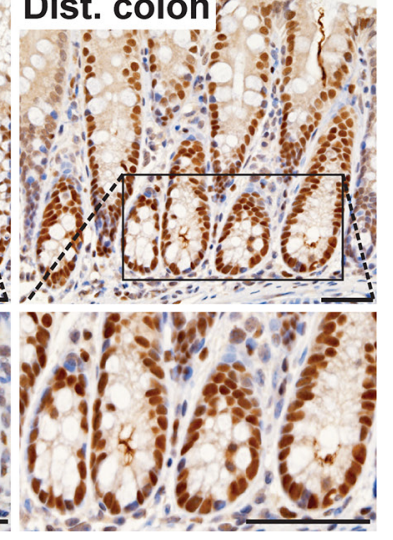

C
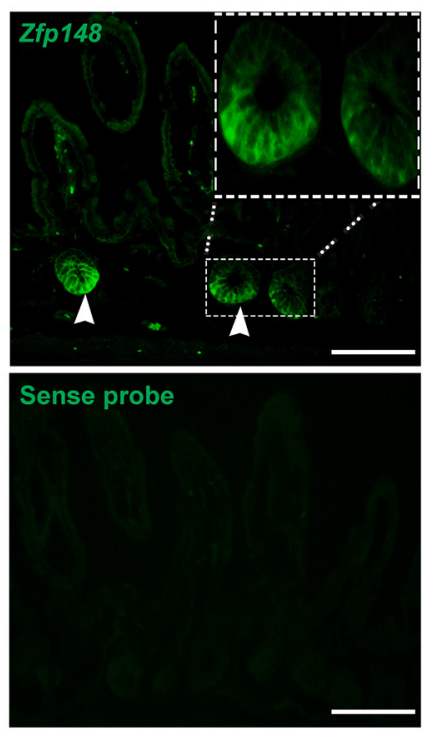

Figure 1: ZBP-89 is highly expressed in CBCs and TA cells. Representative images of immunohistochemistry for ZBP-89 in the (A) small intestine and (B) colon. (C) Zfp148 in situ hybridization in the small intestine. The sense probe was used as the negative control. Scale bar $=100 \mu \mathrm{m}$. Inset of CBCs at $200 \mu \mathrm{m}$ 
cecum and colon (proximal and distal), ZBP-89 was expressed in the lower two-thirds of the colonic gland base (Figure 1B). In addition, ZBP-89 is a ubiquitous protein that is also highly expressed in immune cells $[10,11]$, accounting for expression in scattered cells of the lamina propria.

To localize Zfp148 mRNA, we performed in situ hybridization (ISH) in the small intestine and found that the highest level of mRNA expression occurred at the crypt base (Figure 1C). Scattered cells in the lamina propria also expressed $Z f p 148 \mathrm{mRNA}$, consistent with its known expression in immune cells (Figure 1) [10].

\section{$Z f p 148+$ cells lineage trace in small intestine and colon}

Since Zfp 148 mRNA was expressed at the base of the crypts in CBCs, we generated a Zfp $148 C r e^{E R T 2}$ line from a
BAC clone containing $250 \mathrm{~kb}$ of the $Z f p 148$ promoter to lineage trace its expression. The Zfp148: tdTomato hybrid mice were injected with one dose of tamoxifen (Tx) and then were euthanized at $24 \mathrm{~h}, 3 \mathrm{~d}, 1$ week and 3 weeks post injection. At $24 \mathrm{~h}$ post Tx injection, Zfp 148 positive cells resided at the base of the small intestine and colonic crypts (Figure 2A, 2E). By day 3, the intestinal crypt base and transit-amplifying (TA) cells were consistently labeled (Figure 2B, 2F). By 7d post injection, the tdTomato+ (tdT ${ }^{p o s}$ ) cells populated not only the crypts and TA zone but also labeled scattered cells at the tip of the villi (Figure 2C, 2G). After 3 weeks, Zfp 148 positive cells formed stripes along the entire villus and colonic glands (Figure 2D, 2H). As previously observed for the $L g r 5-E G F P-C r e^{E R T 2}$ reporter [12], we also found that the Zfp148Cre $e^{E R T 2}$ plasmid also generated a variegated lineage trace. While the variegation might indicate stem cell heterogeneity, recent modifications

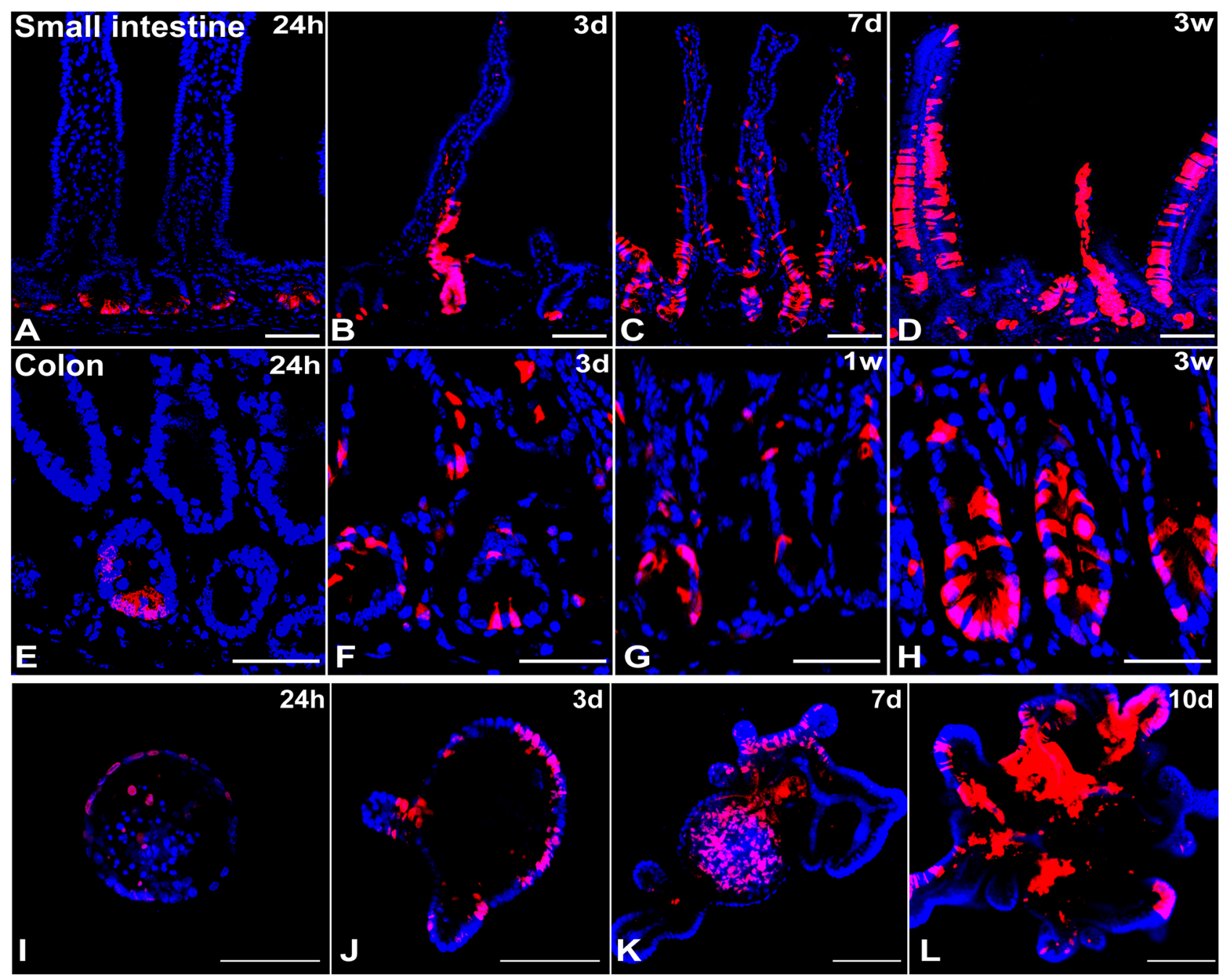

Figure 2: Lineage trace of $Z f p 148$ in mouse small intestine and colon. Representative pictures of $Z f p 148$ lineage trace using Zfp148: tdTomato chimeric mice IP injected with one dose of tamoxifen $0.1 \mathrm{mg} / \mathrm{g}$ body weight (Tx). The small intestine was examined after 24h (A), 3 days (B), one week (C) and three weeks (D). The colon was examined after 24h (E), 3 days (F), one week (G) and three weeks (H). (I-L) Confocal images of intestinal organoids cultured over 10 days after generating from the Zfp148: tdTomato mouse injected with one dose of Tamoxifen and euthanized after $24 \mathrm{~h}$. $\mathrm{N}=4$ mice analyzed per time point. Scale bar $=100 \mu \mathrm{m}$. 
to the original Lgr5 reporter (Lgr5-2A-EGFP-Cre $e^{E R T 2}$ ) created non-variegated lineage tracing, which suggests that the patchy expression is related to transcript stability [13]. Intestinal glands were harvested $24 \mathrm{~h}$ post $\mathrm{Tx}$ injection from the chimeric Zfp148:tdT mice and cultured for 10 days in Matrigel to generate $Z f p 148: t d T^{p o s}$ organoids. Two days after culture, a few Zfp148:tdT ${ }^{\text {pos }}$ cells were visible in the spherical organoids (Figure 2I). By day 3, the Zfp 148:tdT pos cells localized to the crypt-buds and onto the villus-like domain (Figure 2J). At day 7 and 10, Zfp148:tdT pos cells were predominantly located in the crypt-like structures and in the organoid lumen (Figure 2K, 2L). Thus, we concluded

A

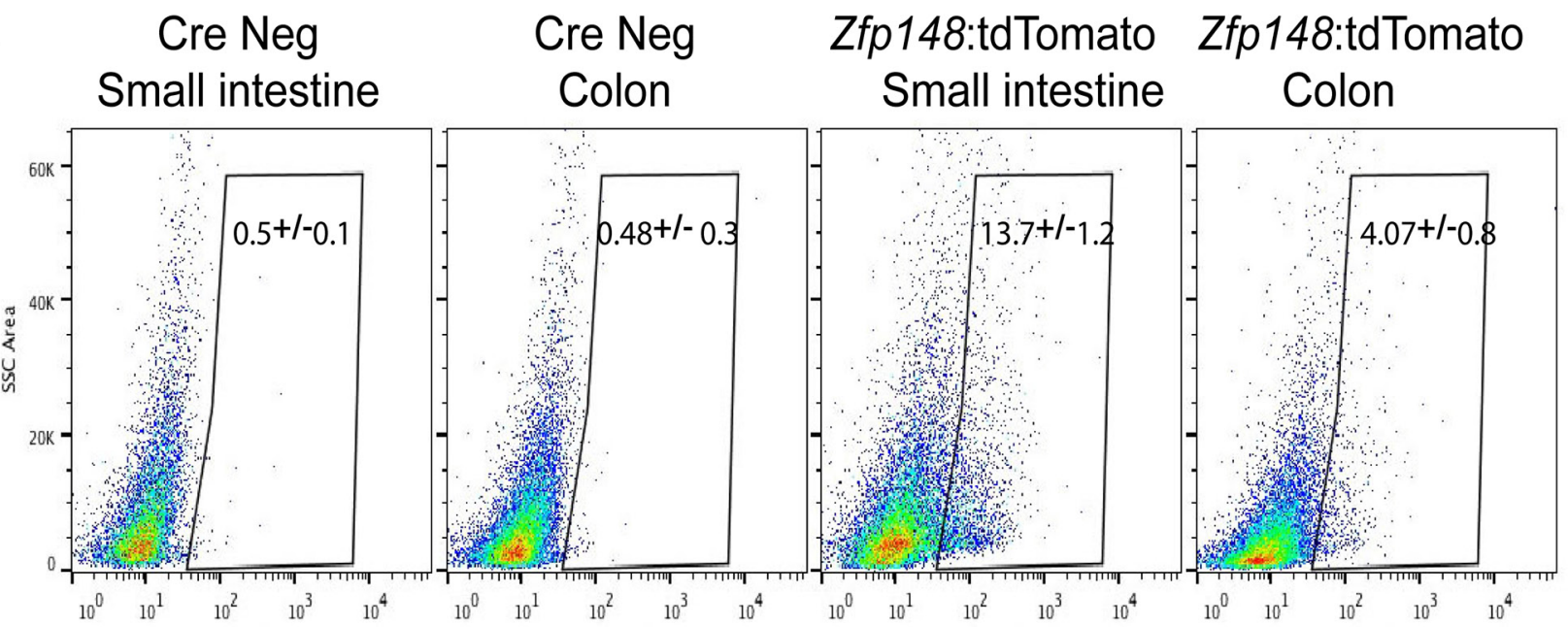

B

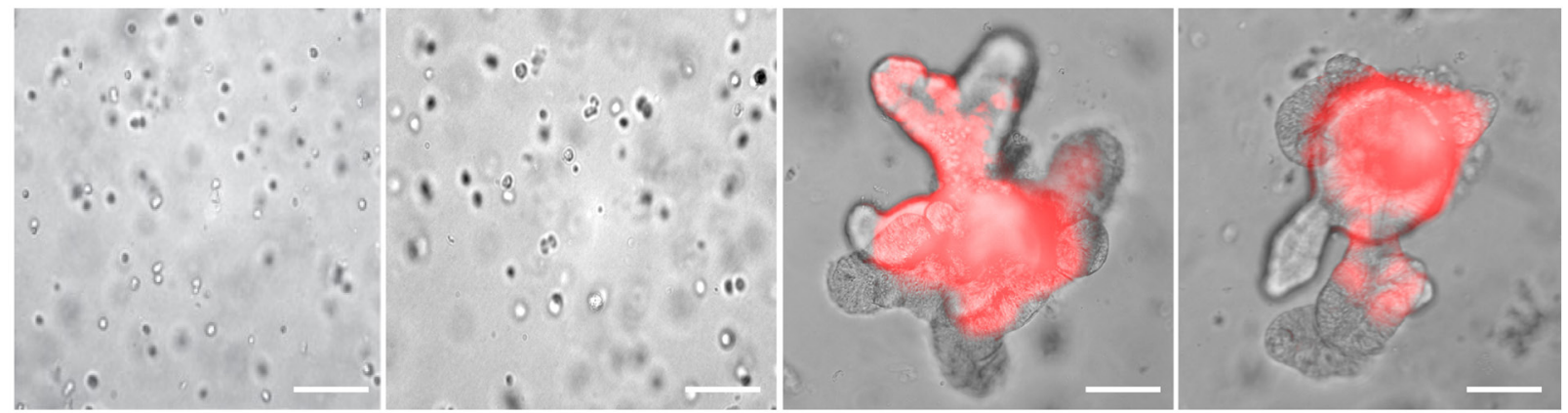

C

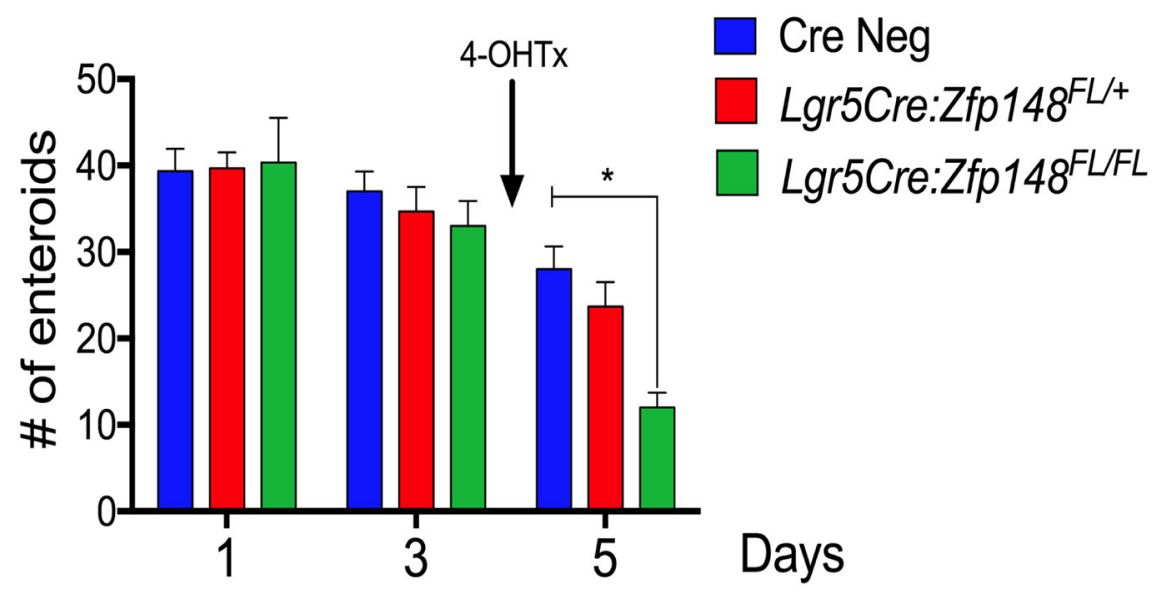

Figure 3: Single cell sorting of $Z f p 148$ : tdTomato $^{+}$cells and deletion of $Z f p 148$ in stem cells. (A) Single cell sorting of $Z f p 148$ : tdTomato positive cells from the small intestine and colon. Gate of fluorescent cells isolated from the CreNeg versus $Z f p 148 C r e^{E R T 2}+$ mice $24 \mathrm{~h}$ after one dose of Tx $(0.1 \mathrm{mg} / \mathrm{g}$ body weight). Shown is the median percentage $\pm \mathrm{SEM}$ for tdTomato + sorted cells from $\mathrm{N}=3 \mathrm{mice}$ per tissue per genotype. (B) Representative images of sorted cells cultured in Matrigel after 3 days in culture. (C) Graph showing total number of small intestine organoids per day. Shown is the mean \pm SEM. ${ }^{* * *} P<0.0001$ ANOVA with Tukey's multiple comparisons. N=3 passages of organoids pooled from 3 mice and cultured in triplicate per time point. Arrow indicates the addition of 4-OH-Tx added after the organoids were in culture for 3 days. Scale bars $=100 \mu \mathrm{m}$. 
that Zfp148:tdT pos cells are highly expressed in the CBC stem cells and can repopulate the entire villi, indicating that ZBP-89 plays a role in both intestine and colonic stem cells.

\section{Zfp148 positive cells form small intestine and colonic organoids}

To further assess the function of ZBP-89 in small intestinal and colonic stem cells, single tdT ${ }^{\text {pos }}$ cells were sorted from a cell suspension of small intestine or colonic mucosa $24 \mathrm{~h}$ post Tx injection (Figure $3 \mathrm{~A}$ ). Both Zfp 148tdT $T^{\text {pos }}$ and Zfp148tdT $T^{\text {neg }}$ cells isolated from the intestine and colon were re-suspended in Matrigel and cultured in complete media. Only the Zfp148td $T^{\text {pos }}$-sorted cells were capable of forming organoids (Figure 3B). Thus, Zfp 148-tdT ${ }^{+}$cells from both the intestine and colon generated budding organoids that continued to express the tdTomato reporter (Figure 3B). To study the function of ZBP-89 in the Lgr5+ CBC stem cells, the Zfp 148 locus was deleted by treating the $\operatorname{Lgr} 5 \mathrm{Cr} e^{E R T 2}: \mathrm{Zfp} 148^{F L /+}$

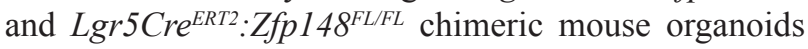
with $4 \mathrm{OH}-\mathrm{Tx}$ after 3 days in culture. After $48 \mathrm{~h}$ of $4 \mathrm{OH}-$ Tx treatment, the number of $\operatorname{Lr} 5 \mathrm{Cre}^{E R T 2}: \mathrm{Zfp} 148^{F L / F L}$ organoids were significantly reduced compared to the Cre Negative (CreNeg) and Lgr5Cre ${ }^{E R T 2}:$ Zfp $148^{F L /+}$ (Figure 3C). Collectively, these results demonstrated that Zfp 148 plays a critical role in the survival of both intestinal and colonic stem cells.

\section{$Z f p 148$ deletion reduces tumorigenesis in $C d x 2$ : $A_{p c}{ }^{F L /+}$ mouse colon}

To evaluate the impact of ZBP-89 on $A p c$-mediated colon polyps, we generated $\mathrm{Cdx} 2 \mathrm{Cre}: \mathrm{Apc}^{F L /+}: \mathrm{Zfp} 148^{F L / F L}$ hybrid mice. The $C d x 2 C r e: A p c^{F L /+}$ mice [14] developed an average of 15 polyps per colon distributed throughout the proximal and distal colon after 5 months (Figure 4A$4 \mathrm{C})$. The number of colon polyps in the $\mathrm{Cd} \times 2 \mathrm{Cre}: \mathrm{Apc} \mathrm{F}^{\mathrm{LL} /+}$

A
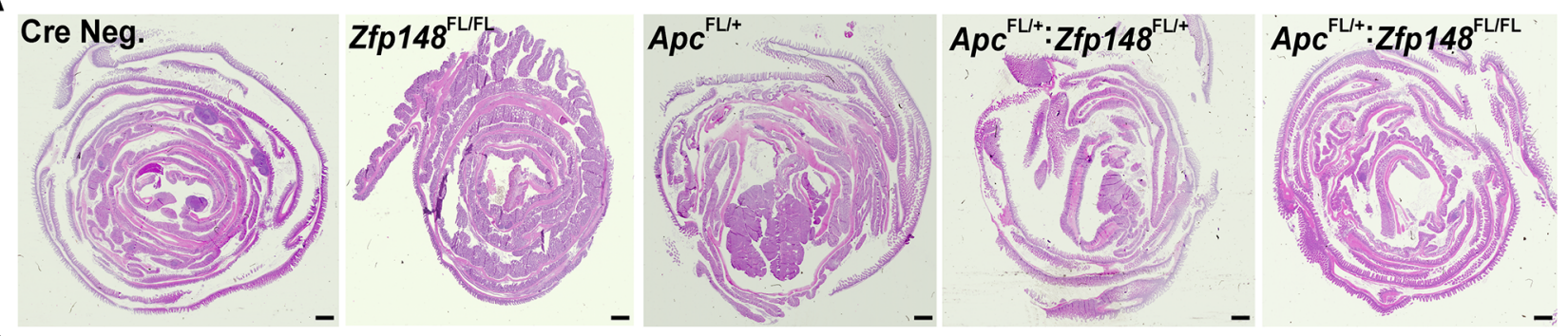

$\mathbf{B}$
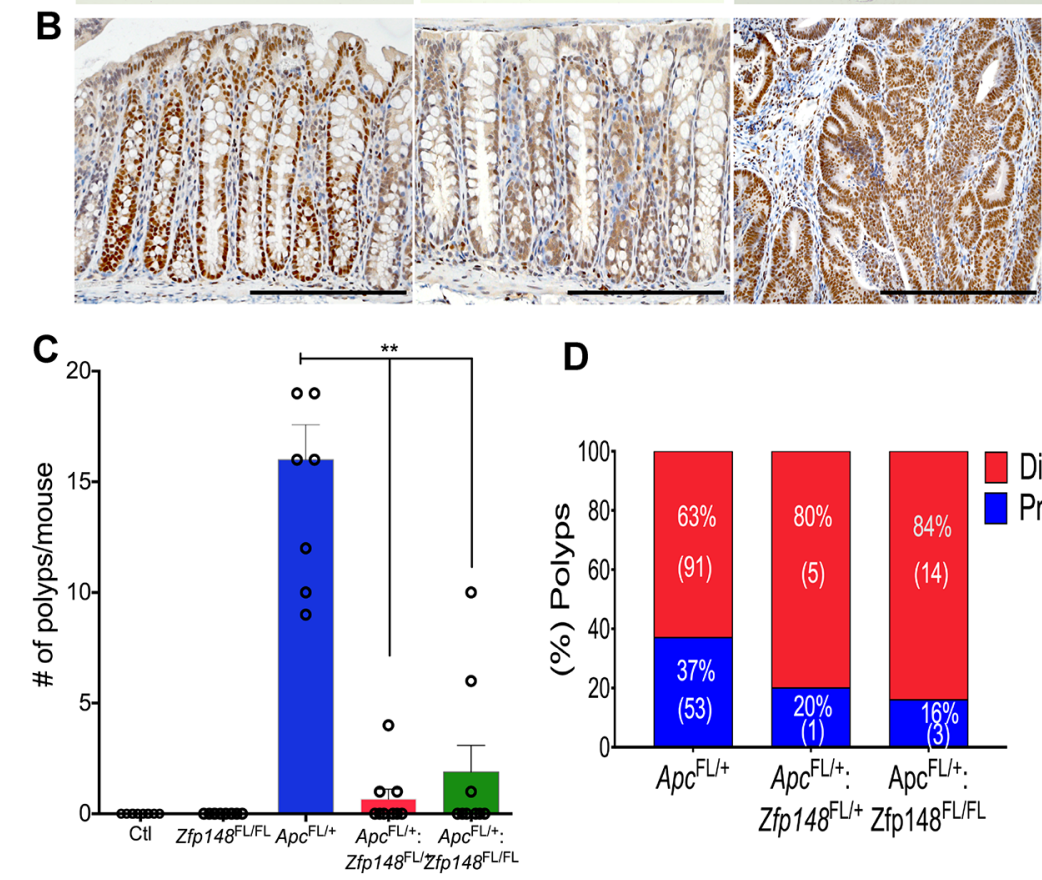

D

E
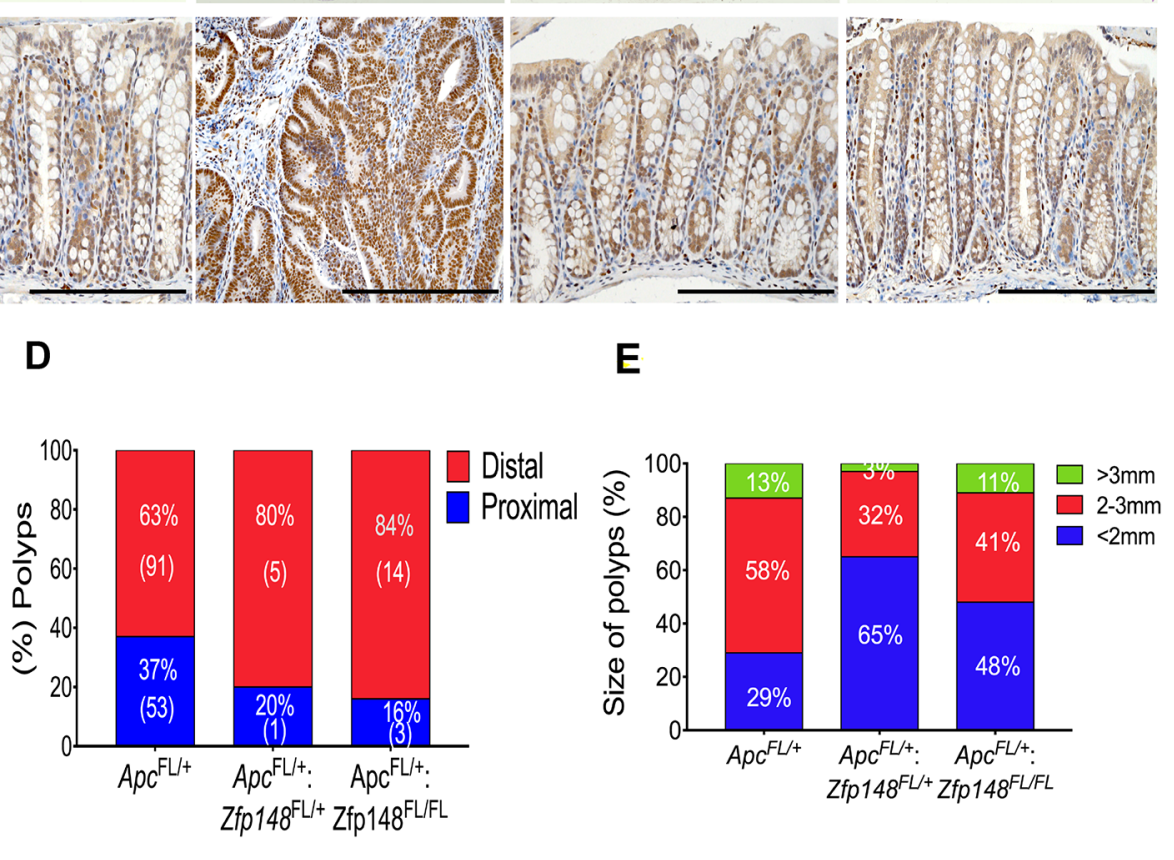

Figure 4: Deletion of $Z \mathbf{f p} 148$ reduces colonic polyps in Cdx2: $\boldsymbol{A p c} \boldsymbol{c}^{F L /+}$ mice. (A) H\&E of Swiss rolls from mouse colons from Cre Negative; $C d x 2: A p c^{F L /+} ; C d x 2: A p c^{F L /+}: Z f p 148^{\mathrm{FL} /+}$ and $C d x 2: A p c^{F L /+}: Z f p 148^{\mathrm{FL} / \mathrm{FL}}$ as indicated. Scale bar $=200 \mu \mathrm{m}$. (B) Representative pictures of ZBP-89 IHC in the colon from the mice shown in (A). Scale bars $=200 \mu \mathrm{m}$. (C) Number of polyps per mouse from the indicated genotypes. Shown are means \pm SEM. $N=9$ mice per genotype ${ }^{* *} P<0.001$, ANOVA Kruskal-Wallis test. (D) Distribution of polyp location as a percentage of total number of polyps per genotype. The number in parentheses equals the total number of polyps identified for that genotype for the 9 mice. (E) Distribution of polyp size as a percentage of total number of polyps per genotype. 
mice was $\sim 4$-fold greater than what we observed when the VillinCre transgene was used to delete Apc [9]. In the $C d x 2 C r e: A p c^{F L /+}$ mice, loss of one or both Zfp 148 alleles reduced the number of colon polyps by $80 \%$ (Figure 4C). Moreover, the location of the polyps that did emerge was more distal in the $C d x 2: A p c^{F L /+}$ mice carrying deleted $Z f p 148$ loci (Figure 4D) and the polyp size was significantly reduced when the $Z f p 148$ alleles were deleted (Figure 4E).

\section{Zfp148 deletion permits colon organoid differentiation}

To directly test the effect of deleting Zfp148 in the hemizygous $A p c$ colonic stem cells, organoids were generated from the colon of $C d x 2 \mathrm{Cre}: A p c^{F L /+}$ mice, which showed a non-budding stem cell morphology (spherical organoids, Figure 5A). However, loss of one or both $Z f p 148$ alleles was sufficient to induce a wrinkled appearance after 3 days of culture that progressed to small buds by day 7 (Figure 5A, 5B, 5D). When both Zfp 148 alleles were deleted, the organoids exhibited extensive budding demonstrating that ZBP-89 was required to maintain stemness. Although loss of one or both $Z f p 148$ alleles in the setting of deleted $A p c$, reduced polyp formation, it did not affect the degree of organoid proliferation as determined by EdU incorporation (Figure 5C, 5E). Although ZBP-89 was required for maintenance of the stem cell niche and cooperates with Wnt signaling, the lack of an effect on cell proliferation suggested that synergy with Wnt signaling affected a different requirement for stem cell maintenance. Therefore, we examined several Wnt targets and found that deletion of Zfp148 in the colon decreased the expression of two
A

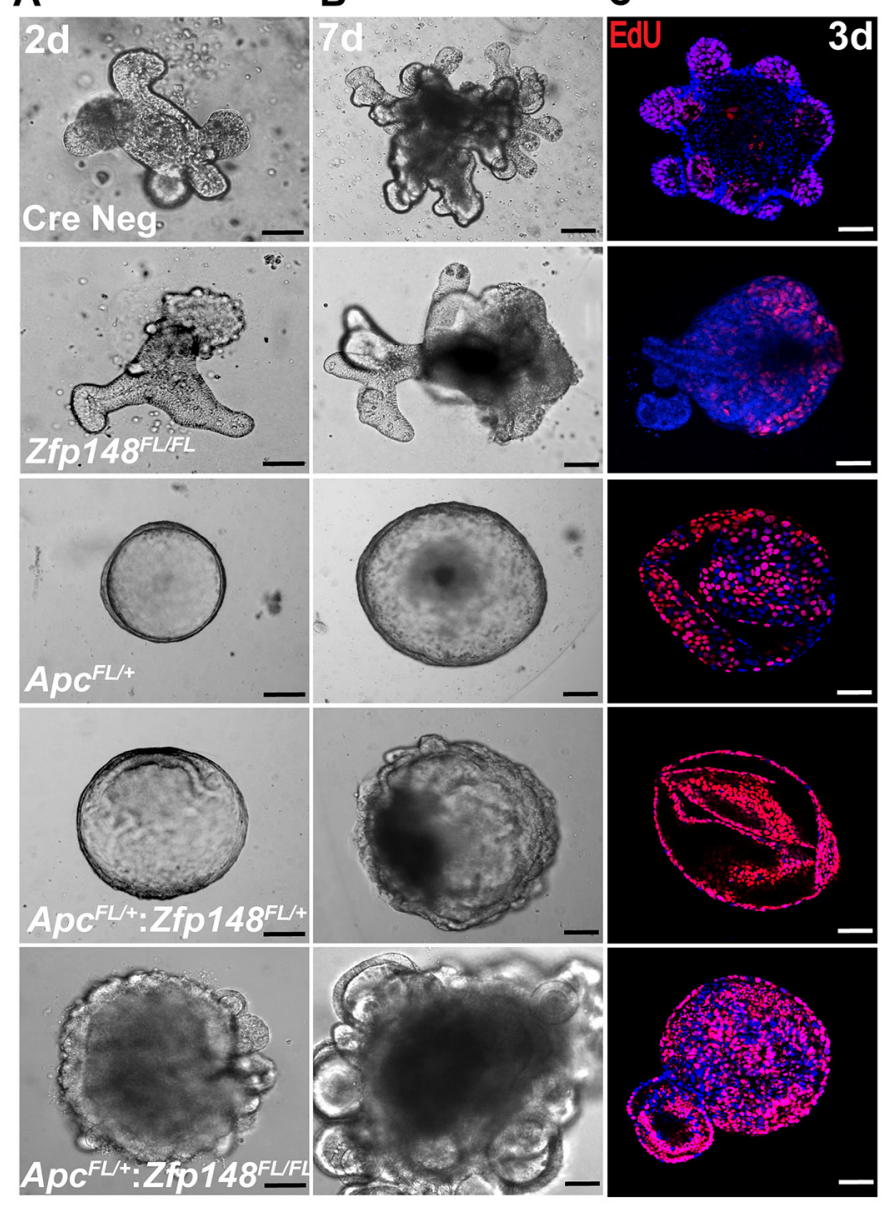

D

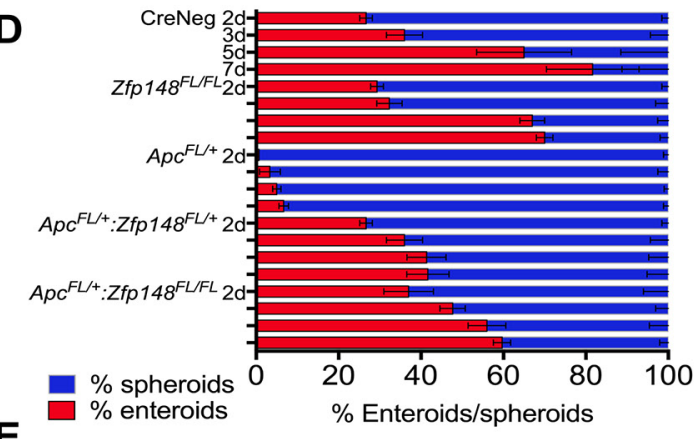

E
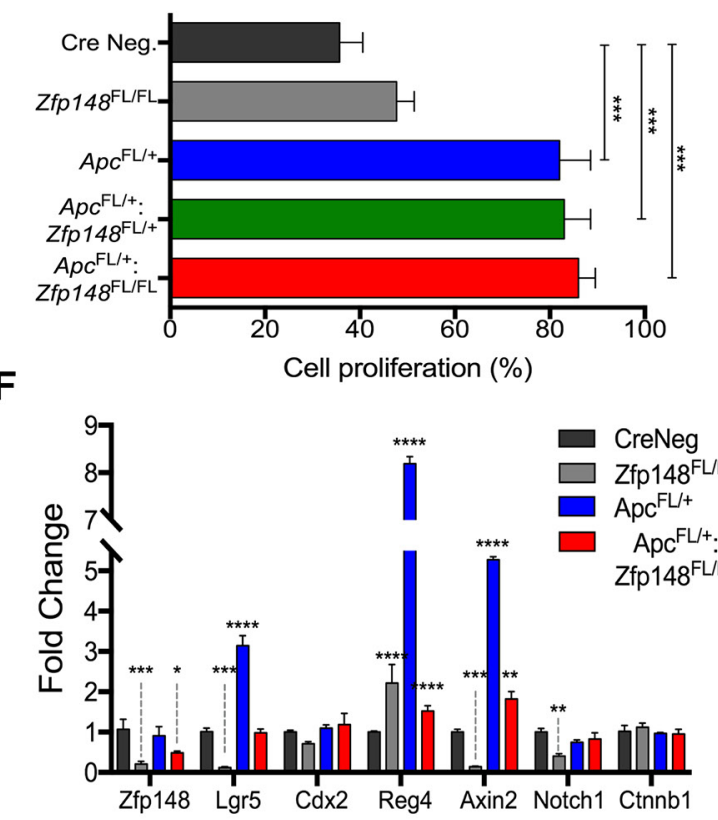

Figure 5: Deletion of $Z \mathbf{f p} 148$ induces cell differentiation in Cdx2: $A p c^{F L /+}$ organoids. (A, B) Images of colonic organoid morphology for each genotype after 2 and 7 days in culture (Cre Neg.; Cdx2: Zfp1448 ${ }^{\mathrm{FL} / \mathrm{FL}} ; C d x 2: A p c^{\mathrm{FL} /+} ; C d x 2: A p c^{\mathrm{FL} /+}: Z f p 148^{\mathrm{FL} /+}$ and $\left.C d x 2: A p c^{\mathrm{FL} /}: Z f p 148^{\mathrm{F} / \mathrm{Fl}}\right)$. (C) Confocal images of EdU incorporation per genotype after 3 days in culture. Scale bar $=100 \mu \mathrm{m}$. (D) Mean percentage \pm SEM for organoid morphology per total structures (organoids/spheroids) at day 2, 3, 5 and 7 after culturing in Matrigel in triplicate for three passages from 3 mice per genotype. (E) Mean percentage \pm SEM of EdU+ nuclei, using 2-3 organoids per image. Five images per genotype per condition were quantified. (F) qPCR using three passages of organoids per genotype. Shown are means \pm SEM, ${ }^{* * * *} \mathrm{P}<0.0001{ }^{* * *} P<0.001,{ }^{* *} P<0.005,{ }^{*} P<0.05$ by two-way ANOVA Tukey's multiple comparisons test. 
direct Wnt target genes Lgr5 and Axin2 consistent synergy between ZBP-89 and $\beta$-catenin. Although Reg4 a Wnt target gene was modulated by deletion of Zfp 148 , it is also regulated by $\mathrm{Cdx} 2$ and Gata 6 transcription factors [1517]. $\beta$-catenin mRNA levels were not affected, perhaps reflecting steady state levels of the protein that are achieved once the organoids become established. Deleting Zfp148 also reduced Notch1, suggesting some crosstalk with the Notch signaling pathway (Figure 5F).

\section{ZBP-89 prevents Apc-deleted organoids from butyrate-induced growth inhibition}

Unlike the small intestine, tumors in the colon emerge in the presence of commensal bacteria that ferment carbohydrates into millimolar amounts of butyrate, a short chain fatty acid (SCFA) with the most potent HDAC inhibitory activity $[18,19]$. Organoid cultures are usually carried out in the absence of butyrate or bacteria. Indeed, butyrate generally suppresses colonic cell growth, which might explain the persistent proliferation of the organoids carrying a mutant $A p c$ allele (Figure 5). Therefore, we examined whether adding butyrate to the organoid cultures affected their growth. Colonic organoids from both WT (CreNeg) and Cdx2Cre:Zfp148 $8^{F L / F L}$ mice were treated with $0.5 \mathrm{mM}$ butyrate, which induced a significant increase in apoptotic cells and suppressed cell proliferation compared to the group with no butyrate (Figure 6A, 6B). Under these conditions, colonic organoids carrying the Apc deletion (Cdx2Cre: $\left.A p c^{F L /+}\right)$ maintained their spheroid shape and thrived in the presence of butyrate $(0.5 \mathrm{mM})$ even though the same concentrations of butyrate were poorly tolerated
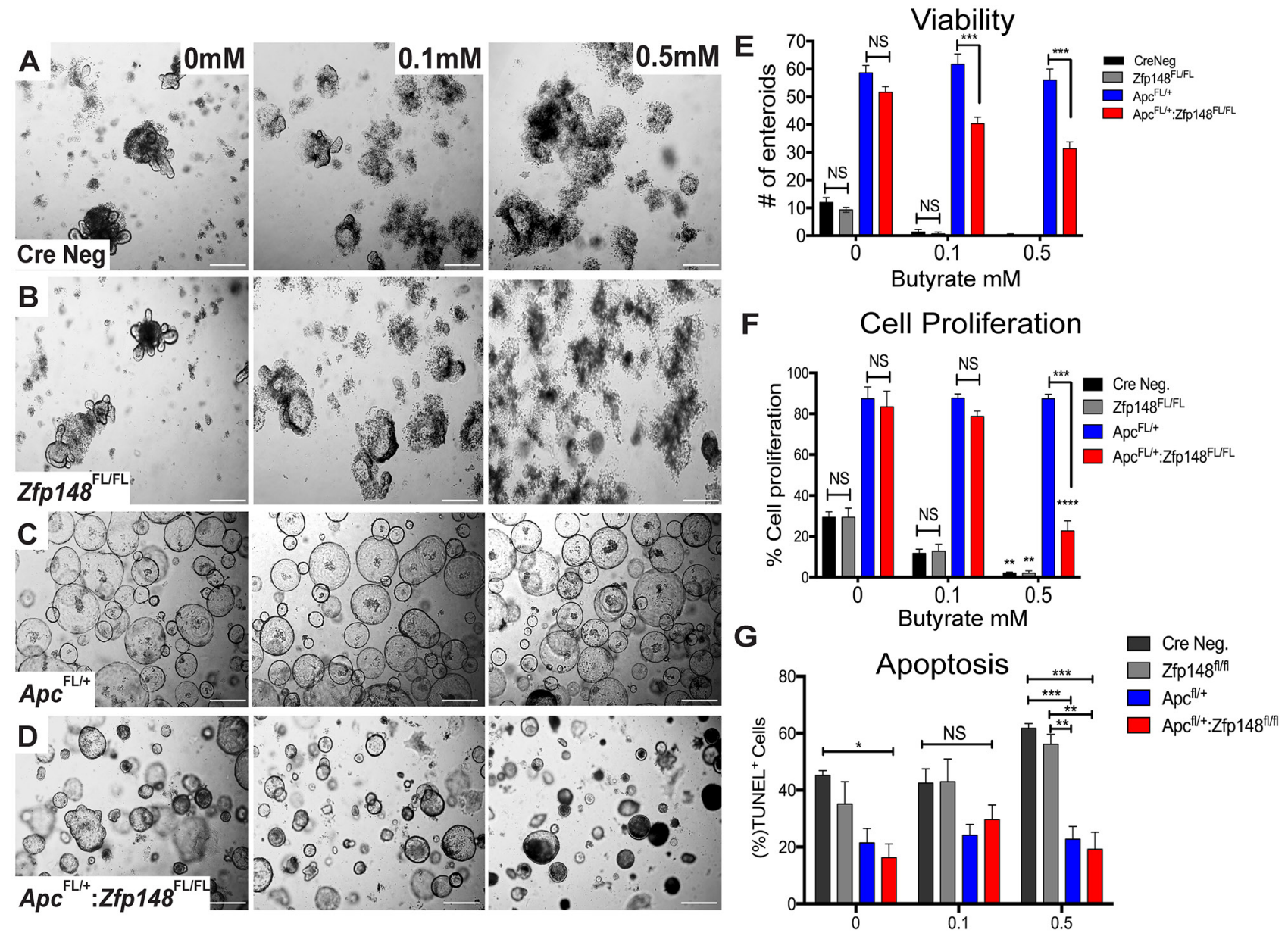

Butyrate $\mathrm{mM}$

Figure 6: ZBP-89 protects Apc mutant organoids against butyrate treatment. (A, B) Representative pictures of Cre Neg; $C d x 2: Z f p 148^{\mathrm{FL} / \mathrm{FL}}$ colonic organoid morphology after $0.1 \mathrm{mM}$ and $0.5 \mathrm{mM}$ butyrate added to the organoid culture medium $(\mathbf{C}, \mathbf{D}) C d x 2$ : $A p c^{\mathrm{FL} /}: Z f p 148^{\mathrm{FL} /+}$ and $C d x 2: A p c^{\mathrm{FL} /+}: Z f p 148^{\mathrm{FL} / \mathrm{F} 1}$ organoids after butyrate treatment. (E) Number of organoids per genotype and per butyrate concentration for three passages of organoids cultured in triplicate per genotype. Shown are the means $\pm \mathrm{SEM}$. ${ }^{* * *} \mathrm{P}=0.001$ using two-way ANOVA with Sidak's multiple comparisons test. (F) Mean percentage \pm SEM of EdU+ nuclei from 2-3 colon organoids per image from a pool of 3 mice per genotype. ${ }^{* *} P<0.001$ and ${ }^{* * *} P<0.0001$ by two-way ANOVA Tukey's multiple comparisons test. (G) TUNEL assay, shown as the percentage of TdT positive cells for each population per number of DAPI positive cells. ${ }^{*} P<0.05,{ }^{* *} P<0.001$ and ${ }^{* * *} P<0.0001$ by two-way ANOVA Tukey's multiple comparisons test. 
by normal colon organoids (Figure 6C, 6D). However, deletion of $Z f p 148$ (Cdx2Cre: $A p c^{F L /+}: Z f p 148^{F L / F L}$ ) reduced organoid proliferation in the presence of butyrate (Figure $6 \mathrm{E}, 6 \mathrm{~F})$, but there was no significant increase in apoptosis (Figure 6G), suggesting that loss of Zfp 148 in the presence of butyrate might initiate cellular senescence (growth arrest) in contrast to apoptosis [20]. By contrast, intestinal organoids exhibited greater sensitivity to butyrate (Figure 7A-7E). Senescence was observed in the $A p c$ and $A p c$ plus Zfp 148-deleted intestinal organoids even at $0.1 \mathrm{mM}$ butyrate, while both the Cre Neg and Zfp148-deleted organoids without the $A p c$ deletion were already apoptotic at this lower butyrate concentration (Figure 7F).

To examine whether ZBP-89 colonic organoids exhibited cellular senescence, we determined the levels of SA- $\beta$ Gal in organoid cultures treated with increasing amounts of butyrate $(0,0.1,0.5 \mathrm{mM})$ (Figure 8$)$. We found that both CreNeg and Cdx2Cre: $\mathrm{Zfp} 148^{F L / F L}$ organoids were senescent and subsequently apoptotic with increasing concentrations of butyrate (Figure $8 \mathrm{~A}, 8 \mathrm{~B}, 8 \mathrm{E}$ ). By contrast, $\mathrm{Cd} \times 2 \mathrm{CreApc}^{F L /+}$-derived organoids did not undergo senescence unless Zfp148 was deleted (Figure 8C-
$8 \mathrm{E})$. Since senescence is mediated by the cyclin-dependent inhibitor Cdkn2a [20], we determined its expression levels using RNA extracted from the organoids before and after butyrate treatment. Indeed, we found a significant increase in Cdkn2a mRNA with deletion of Zfp 148 but more dramatically when the organoids were treated with butyrate (Figure 8F, 8G). Surprisingly, butyrate strongly suppressed $Z f p 148$ gene expression contributing to the increase in Cdkn2a (Figure 8F, 8G).

Feng et al. previously showed that ZBP-89 binds directly to and represses the $C D K N 2 A$ promoter in a lung cancer cell line by recruiting HDACs [6]. Therefore, to determine whether butyrate regulated ZBP-89 binding to the $C d k n 2 a$ promoter, we performed Chip-Seq using STC1 cells, a mouse intestinal cell line and found that ZBP-89 binding to the mouse Cdkn2a promoter decreases (Figure 9A). To determine if butyrate suppression of ZBP-89 binding induced $C D K N 2 A$ gene expression and senescence in colon cancer cell lines, the CRC cell line SW480 was treated with butyrate for 1,3 and $16 \mathrm{~h}$. ChiP-qPCR showed that butyrate reduced ZBP-89 binding to the CDKN2A promoter (Figure 9B), which corresponded to an increase
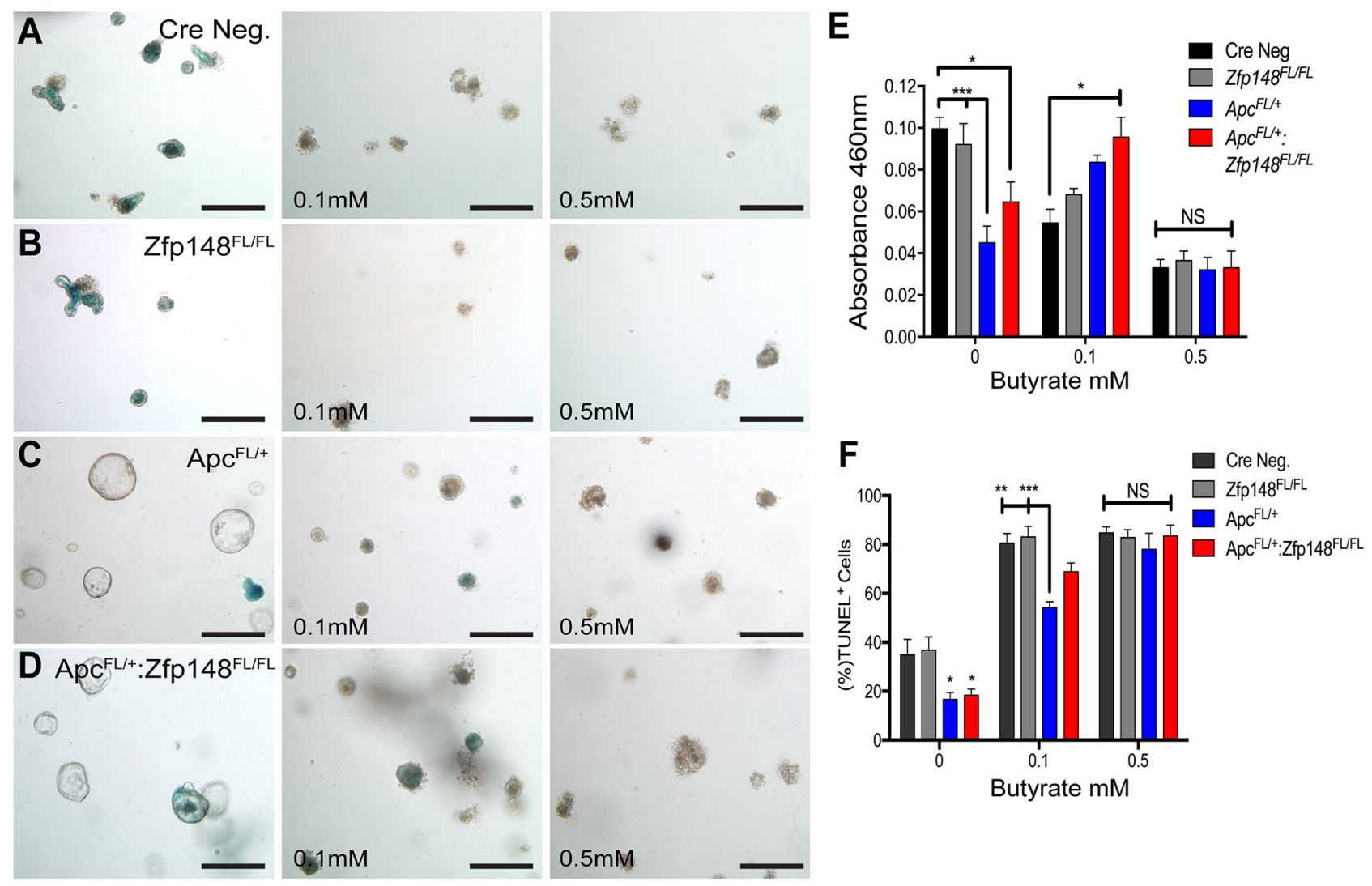

Figure 7: Intestinal organoids show greater sensitivity to butyrate than colon organoids. Representative pictures of intestinal organoids stained for senescence-associated beta galactosidase (SA- $\beta \mathrm{Gal}$ ) activity before and after treating with increasing butyrate

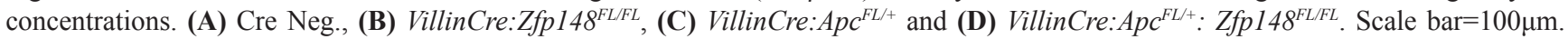
(E) Spectrophotometric quantitation of intestinal organoids SA- $\beta$ Gal activity at $A_{460}$. (F) TUNEL assay, shown as the percentage of TdT positive cells for each population per number of DAPI positive cells. ${ }^{*} P<0.05,{ }^{* *} P<0.001$ and ${ }^{* * *} P<0.0001$ by two-way ANOVA Tukey's multiple comparisons test. 
in $C D K N 2 A$ gene expression in SW480 in addition to Caco2 and HT-29 cell lines (Figure 9C, 9D). To determine if the increase in CDKN2A ( $16^{I N K 4 A}$ ) expression corresponded directly to silencing of ZBP-89 gene expression in the colonic cell lines (SW480, Caco-2 and HT-29), ZNF148 was knocked down using siRNA oligos. Indeed, $C D K N 2 A$ was significantly induced and corresponded to reduced ZNF148 mRNA expression (Figure 9E, 9F). Therefore, as observed in our mouse model, butyrate induces $C D K N 2 \mathrm{~A}$ gene expression and presumably cellular senescence through its ability to suppress ZNF148 gene expression.

\section{DISCUSSION}

The studies reported here demonstrate that ZBP89 is expressed in CBCs and plays a role in stem cell maintenance and cellular differentiation. We recently reported that ZBP-89 synergizes with Wnt signaling by directly inducing $\beta$-catenin gene expression [9]. Consequently, the increase in ZBP-89-mediated gene expression sustains elevated levels of this protooncogene. Conversely $\beta$-catenin induces the expression of ZNF148 [9]. As previously suggested [9], the feedforward regulation of these two transcription factors contributes significantly to Wnt-driven transformation from both intestine and colonic stem cells [21]. Specifically, we show here that fewer and smaller polyps formed when both the Zfp148 and Apc loci were conditionally deleted using the colon-specific $C d x 2 C r e$ transgene. Zfp 148 deletion corresponded to increased organoid budding indicating loss of stemness that presumably retards transformation of the colonic stem cell niche. Surprisingly, neither Zfp 148 deletion nor butyrate alone was sufficient to inhibit organoid proliferation in the context of a deleted $A p c$

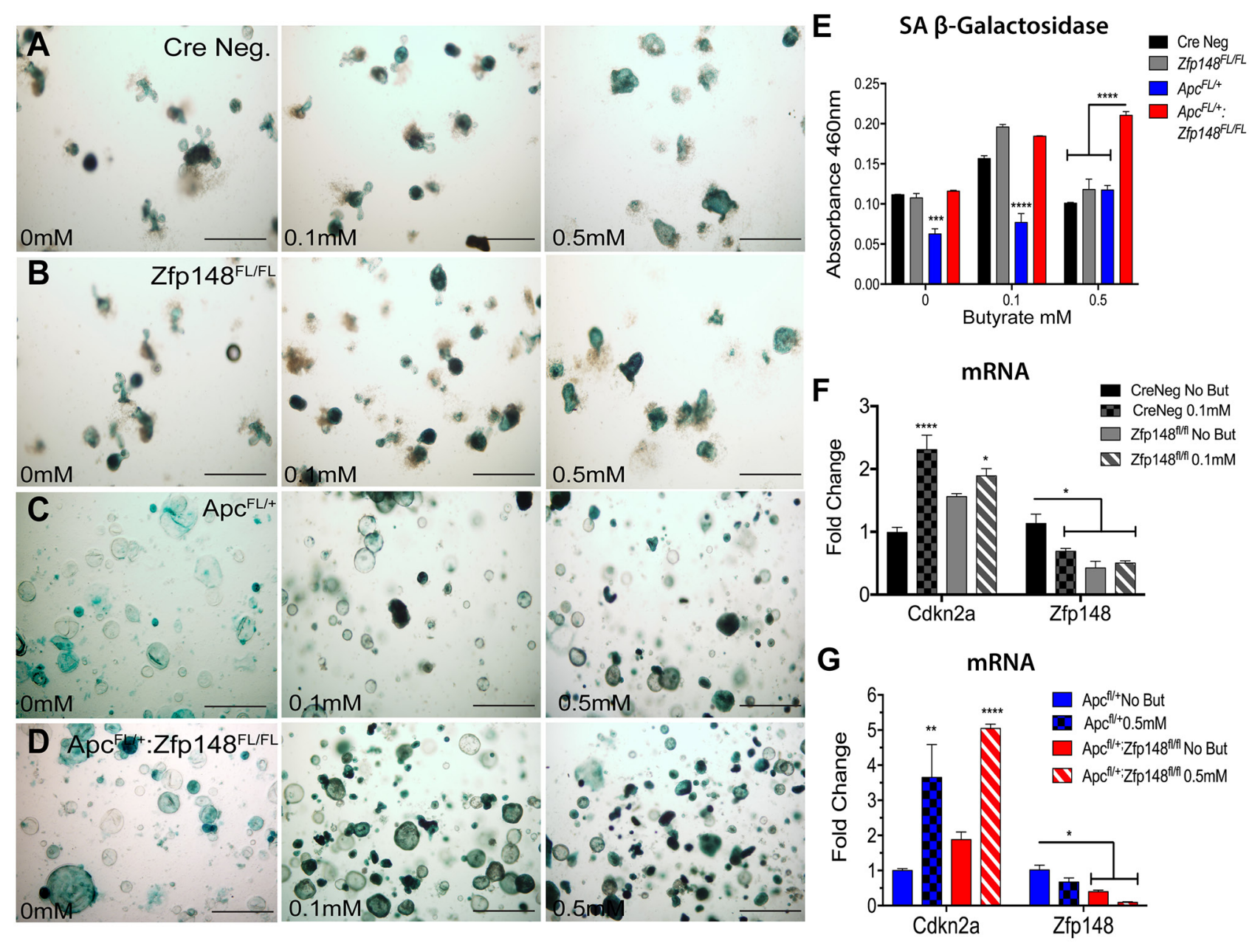

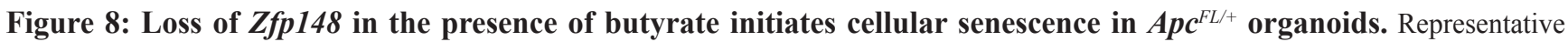
pictures of colonic organoids stained for senescence-associated beta galactosidase (SA- $\beta$ Gal) activity before and after treating with increasing butyrate concentrations (A) Cre Neg., (B) Cdx2Cre:Zfp148 ${ }^{F L / F L}$, (C) Cdx2Cre:Apc ${ }^{F L /+}$ and (D) $C d x 2 C r e: A p c^{F L /+}: Z f p 148^{F L / F L}$. Scale bar $=100 \mu \mathrm{m}$. (E) Spectrophotometric quantification of colonic organoids SA- $\beta$ Gal activity at $\mathrm{A}_{460^{\circ}}$ (F) qPCR for $C d k n 2 a$ and $Z f p 148$ using three passages of CreNeg and $C d x 2: Z f p 148^{\mathrm{FL} / \mathrm{FL}}$ colonic organoids incubated with $0.1 \mathrm{mM}$ butyrate. (G) qPCR for $C d k n 2 a$ and $Z f p 148$ using three passages of $C d x 2: A p c^{\mathrm{FL} /+}: Z f p 148^{\mathrm{FL} /+}$ and $C d x 2: A p c^{\mathrm{FL} /+}: Z f p 148^{\mathrm{FL} / \mathrm{Fl}}$ colonic organoids incubated with $0.5 \mathrm{mM}$ butyrate. ${ }^{*} P<0.05$, ${ }^{* *} P<0.001$ and ${ }^{* * *} P<0.0001$ by two-way ANOVA Tukey's multiple comparisons test. 
locus, but instead synergistically functioned to suppress the stem cell phenotype.

HDAC inhibitors such as butyrate induce cellular senescence by increasing cyclin-dependent inhibitors, e.g., $p 21^{\text {wafl }}, p 16^{I N K 4}[22-24]$. In the colon, butyrate levels are lowest in the distal colon and deep within the crypts away from luminal bacteria $[18,19]$. We previously showed that ZBP- 89 directly binds the $p 21^{\text {wafl }}$ promoter and potentiates butyrate induction of this cyclin-dependent inhibitor, which is also a gene target of several transcriptional regulators including p53 and cMyc [2]. Although ZBP-89 forms a protein-protein interaction with p53 and prevents its nuclear export and degradation in the cytoplasm [3], the in vivo significance of the interaction was not readily apparent. A possible mechanic was through the induction p53 regulation of $p 21^{\text {wafl }}$, and subsequently cellular senescence. Recently, Lindahl and co-workers reported that ZBP-89 blocks Apc mutant polyp development in the intestine by inhibiting p53-mediated activity [25]. They observed no effect on cell proliferation or apoptosis in the early intestinal tumors, and suggested that reduced tumor initiation was due to a change in cell fate. Here we demonstrate that butyrate coupled with deletion of Zfp148 was required to significantly enter a senescent phase of slowed cell growth, resulting in fewer and smaller colon polyps in vivo as well as fewer and smaller
A

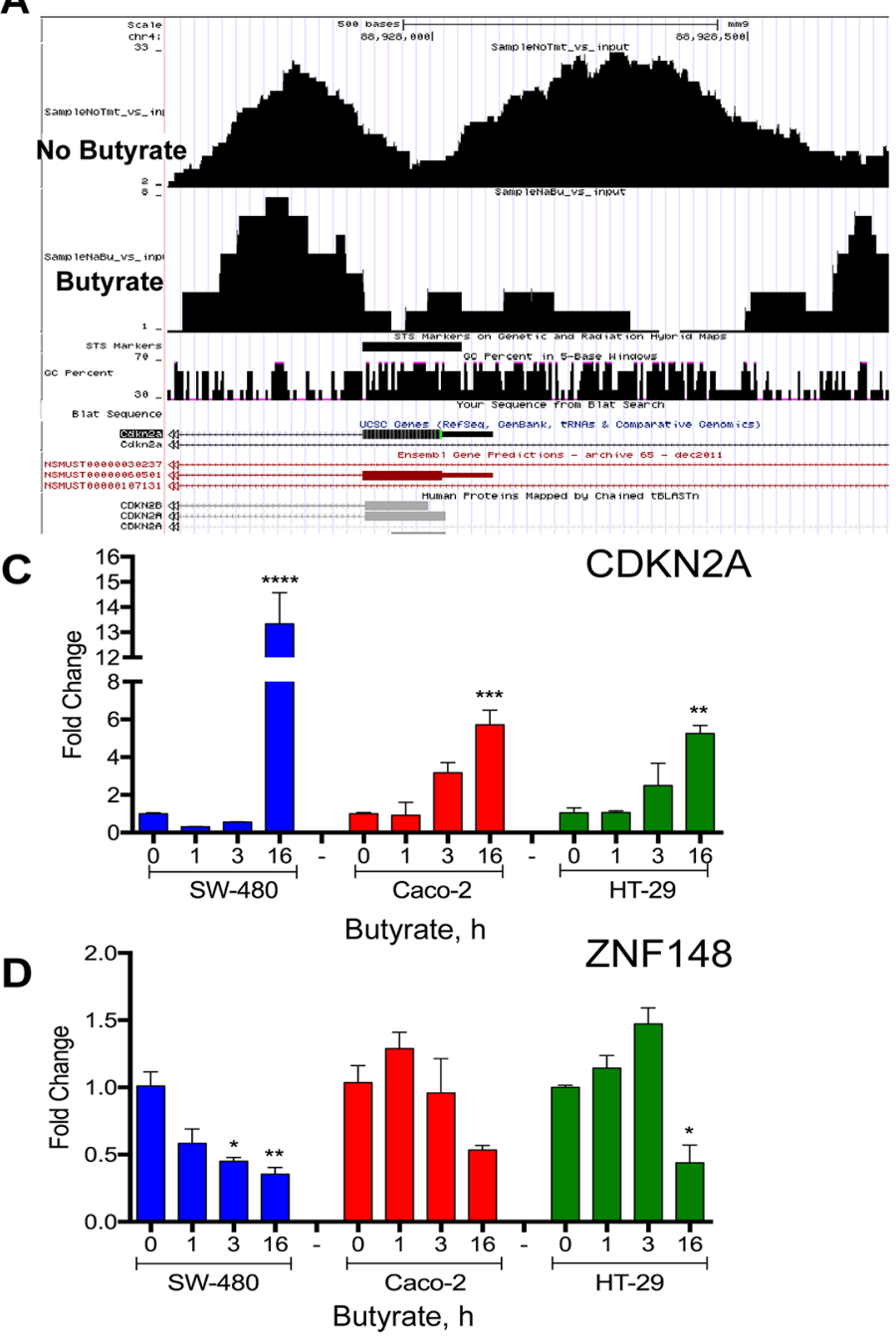

B
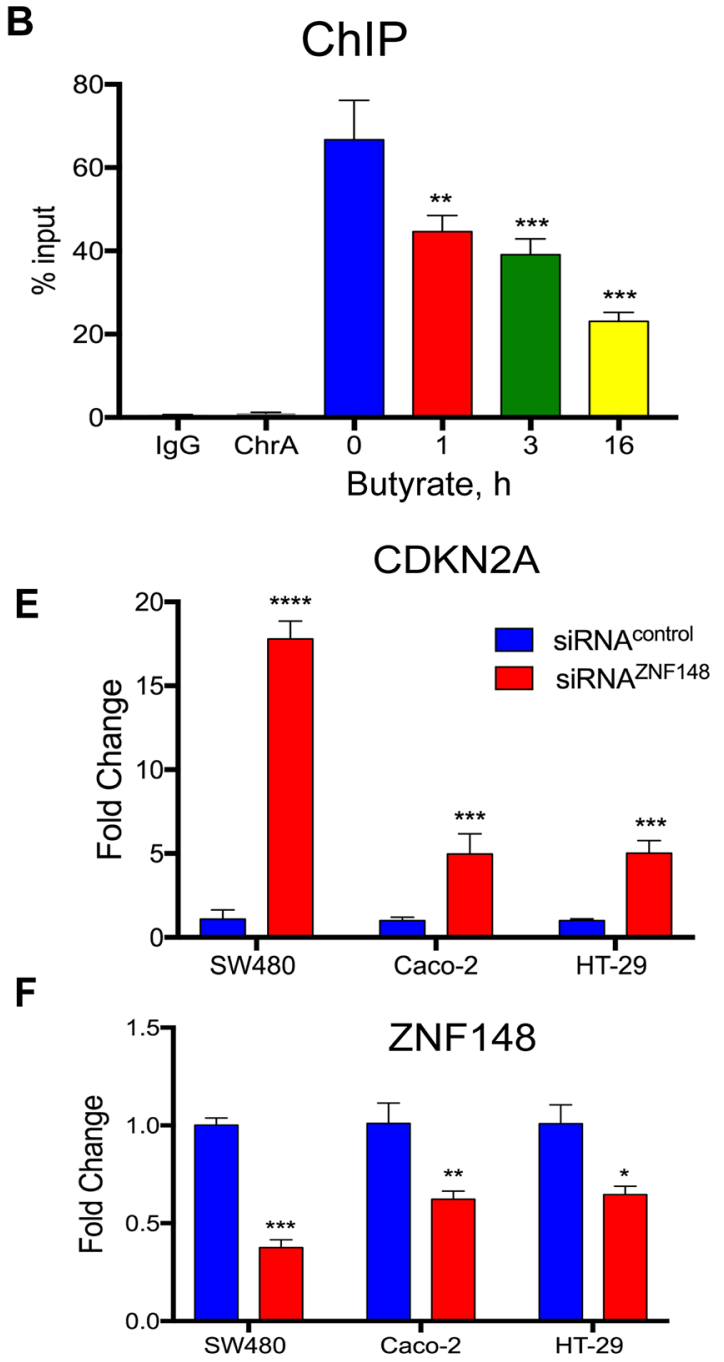

Figure 9: Butyrate decreased ZBP-89 binding to the mouse and human p16 $^{\text {Ink } 4 a}$ promoter. (A) ChIP-Seq of mouse STC-1 cells treated with $2.5 \mathrm{mM}$ butyrate for $6 \mathrm{~h}$. Chromatin precipitated with ZBP-89 antibody was analyzed in the UCSC genome GRC m38/ mm10 browser. (B) Chromatin Immunoprecipitation of SW480 cells treated with butyrate for 1, 3 and 16h. Occupancy of the CDKN2A promoter by ZBP-89 determined by qPCR was plotted as a function of the input. (C) SW480, Caco-2 and HT-29 cells treated with butyrate for 1, 3 and $16 \mathrm{~h}$ were analyzed by qPCR for CDKN2A mRNA and (D) ZNF148 mRNA. (E) SW480, Caco-2 and HT-29 cells incubated for $24 \mathrm{~h}$ with ZNF148 siRNA or siRNA scrambled control oligos and then treated with butyrate for 1, 3 and $16 \mathrm{~h}$ were analyzed by qPCR for CDKN2A mRNA and (F) ZNF148 mRNA. Shown are means \pm SEM, ${ }^{* * * *} P<0.0001,{ }^{* * *} P<0.001,{ }^{* *} P<0.05$, by one-way ANOVA multiple comparisons test. 
colonic organoids. As such, ZBP-89 has been shown to induce cellular senescence when overexpressed in lung cancer cells due to its ability to recruit HDACs to the cyclin-dependent inhibitor $p 16^{I N K 4 A}$ promoter [6]. Thus, a contribution of ZBP-89 to the stem cell phenotype is likely related to its ability to recruit HDACs to specific promoters regulating the expression of genes that inhibit the cell cycle.

Colonic fermentation of dietary carbohydrates is the exclusive purview of commensal bacteria with butyrate being the most frequently studied of the abundant SCFAs [18]. Butyrate exhibits a number of functions ranging from colonocyte fuel source to chromatin modulation through inhibition of HDACs [26, 27]. Yet, therapy with this SCFA to suppress inflammation and transformation has been mixed, perhaps as a result of the different cellular pathways it regulates [28-30]. Moreover, cellular regulation by butyrate depends on the metabolic and proliferative status of the cell [31-33]. Typically, butyrate levels are lowest in the distal colon due to rapid fermentation of dietary fiber and use as a primary carbon source by colonocytes in the proximal colon. This in turn correlates with the propensity of colorectal tumors to develop in the distal colon where butyrate levels are the lowest $[18,32]$. Indeed, the few polyps that developed in the mice carrying deleted $Z f p 148$ alleles were in the distal colon. In addition, butyrate levels at the base of the colonic crypt where the stem cells reside are estimated to be in the micromolar range, significantly lower than the millimolar levels at the luminal surface [32]. Consequently, we found that treating normal colonic organoids with millimolar amounts of butyrate induced senescence and subsequently apoptosis. However, organoids from $A p c$-deleted colons in which Wnt signaling is elevated protected against butyratemediated apoptosis and were observed to proliferate. By contrast, Zfp148 deletion abolished the protective effect of the $A p c$ deletion. Like butyrate, Zimberlin et al. showed that intestine specific deletion of both HDAC1 and HDAC2 in vivo or chemical ablation with a class I-specific HDAC inhibitor MS-275 reduced proliferation, expression of stem cell markers and decreased the clonogenic capacity of intestinal organoids [34]. Thus, HDACs are an essential factor in stem cell maintenance and explains in part how ZBP-89 contributes to the stem cell phenotype in the colon. We conclude that in both the small intestine and colon, ZBP-89 contributes to stem cell maintenance as a modulator of the Wnt pathway, but also through recruitment of HDACs. However intestinal organoids were more sensitive to the senescent and apoptotic effects of butyrate than those prepared from the colon. Thus, in the colon, where a gradient of butyrate is present as a function of the microbiota, we would predict that a ZBP89-HDAC complex would inhibit CDKN2A and block growth inhibition as a function of being exposed to this potent natural HDAC inhibitor.
In summary, ZBP-89 plays an essential role in maintaining stemness in both the intestine and colon. As a known mediator of butyrate-dependent regulation in cell lines [2, 4], it appears that the ability of ZBP-89 to interact with HDACs contributes to its ability to synergize with $\beta$-catenin to resist the senescent effects of butyrate in $A p c$ mutant stem cells where Wnt signaling and $\beta$-catenin protein levels are high. Interestingly, there appears to be tissue specific differences in the ability of the small intestine versus the colon to resist butyrate-induced senescence. Taken together, these results provide at least a partial explanation for why ZBP-89 protein expression contributes to the formation of colonic adenomas and progression during the early stages colon cancer $[9,35]$.

\section{MATERIALS AND METHODS}

\section{Animal models}

Generation of $Z f p 148^{F L / F L}$ mice on a C57BL/6 genetic background was previously described [8]. $A p c^{F L /+}, Z f p 148^{F L /+}$ and $Z f p 148^{F L / F L}$ mice were bred to the Cdx2Cre mouse line [14] or VillinCre [36] to generate mice that were heterozygous for the $A p c$ allele alone or with the $Z f p 148^{F L /+}$ and $Z f p 148^{F L F L}$ genotypes (Cdx2Cre: $A p c^{F L /+}: Z f p 148^{F L / F L}$ or $A p c^{F L /+}: Z f p 148^{F L /+}$ or VillinCre: $\mathrm{Apc}^{\mathrm{FL} /+}: \mathrm{Zfp} 148^{\mathrm{FL} / \mathrm{FL}}$ [9]). To generate the Zfp $148 \mathrm{Cr} e^{E R T 2}$ transgene, the $C r e^{E R T 2}$ IRES_eGFP cDNA cassette was inserted downstream of the mouse Zfp148 ATG in exon 4 prepared from BAC clone RP23-207B1 that contains 250 $\mathrm{kb}$ of the $Z f p 148$ mouse gene (JrGang Cheng, University of North Carolina). The purified Zfp148Cre $e^{E R T 2}$ transgene was microinjected into the pronuclei of fertilized C57BL/6 x SJL chimeric mouse eggs (University of Michigan Transgenic Core). Three founder lines (725, 730 and 740) were bred to the Rosa26-LoxSTOPLox-tdTomato reporter mice (Rosa-tdT) (B6.Cg-Gt(ROSA)26Sor ${ }^{\text {tm27.1(CAG- }}$

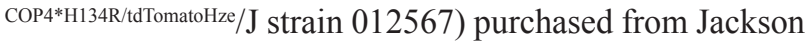
Laboratory. The lines were ultimately backcrossed to C57BL/6 mice over two years. To lineage trace Zfp148 expression in the intestine and colon, the line with the highest fluorescent reporter expression was selected (line 730). Mice were maintained under the University of Michigan Animal Care and Use Committee, which maintains an American Association of Assessment and Accreditation of Laboratory Animal Care facility and approved all methods and procedures used.

\section{Immunohistochemistry}

Immunohistochemistry was performed using the diaminobenzidine (DAB)-based staining technique (Abcam, ab4238). After de-paraffinization and rehydration, antigen retrieval was performed by boiling tissue sections in a microwave for $10 \mathrm{~min}$ with $10 \mathrm{mM}$ sodium citrate buffer $(\mathrm{pH}$ 
6.0). Tissue sections were preincubated with $0.3 \%$ hydrogen peroxide and nonspecific binding sites were blocked with $20 \%$ normal goat serum (Jackson ImmunoResearch, West Grove. PA). A polyclonal antibody to the conserved C- terminal residues (611-794) of ZBP-89 (1:1000, sc48811; Santa Cruz Biotechnology Inc., Santa Cruz, CA) was incubated for $2 \mathrm{~h}$ in a humidified chamber and then incubated with horseradish peroxidase (HRP)- conjugated secondary antibody for $30 \mathrm{~min}$. The sections were stained with DAB and counterstained with Mayer hematoxylin, prior to mounting in Toluene Permount (Fisher Scientific, Waltham, MA).

\section{In situ hybridization}

The tissue was embedded in O.C.T. Compound (Tissue -Tek), sectioned, placed on slides and then was re-hydrated in DEPC-treated water prior to a $1 \mathrm{~h}$ prehybridization incubation in 50\% formamide/Denhardt's solution at $55^{\circ} \mathrm{C}$. The single strand DNA probes (ssDNA) labeled at the 5' end with 6-FAM were reconstituted in sterile RNAse-free water, diluted to a working concentration of $50 \mathrm{ng} / \mathrm{ml}$ with hybridization buffer and incubated for $48 \mathrm{~h}$ at $60^{\circ} \mathrm{C}$. Slides were stringently washed with $50 \%$ formamide in $5 \mathrm{X}$ sodium citrate saline (SSC, $\mathrm{pH}$ 7.0) buffer for $2 \mathrm{~min}$ at $40^{\circ} \mathrm{C}$. Samples were rinsed with DEPC-treated water and allowed to air-dry prior to mounting with Prolong Gold Antifade reagent with DAPI (ThermoFisher; Scientific). The following probes were used:

Zfp148 antisense probe 1: 5'6-FAM/ACCGACT ATTAGTCCAAAGTGGGACTT/

Zfp148 sense probe: 5'6-FAM/TGGCTGATAA

TCAGGTTTCACCCTGAA/

Sense strand sequence for $Z f p 148$ was used as negative control.

\section{Mouse organoid generation}

Intestinal or colonic mucosa was minced into $5 \mathrm{~mm}$ pieces on ice followed by gland dissociation in $2 \mathrm{mM}$ EDTA/PBS at $4^{\circ} \mathrm{C}$ for $30 \mathrm{~min}$ for intestinal tissue and $4 \mathrm{mM}$ EDTA/PBS at $4^{\circ} \mathrm{C}$ for $60 \mathrm{~min}$ for colonic tissue. After filtration through a $70 \mu \mathrm{m}$ cell strainer (BD Bioscience) for intestine and a $100 \mu \mathrm{m}$ cell strainer (BD Bioscience) for colon, the suspension was centrifuged at $200 \times \mathrm{g}$ for $5 \mathrm{~min}$. Intestinal glands were re-suspended in $50 \mu \mathrm{l}$ of Matrigel supplemented with Advanced DMEM/F12 (Invitrogen) containing $50 \%$ of Wnt, R-Spondin, Noggin conditioned media generated from the L-WRN (cell line ATCC $($ CRL$3276^{\mathrm{TM}}$ ) with B27 and N2 1X supplements (ThermoFisher; Scientific) plus EGF (50ng/ml, Invitrogen). To generate colon organoids, the media was mixed with Matrigel containing CHIR99021 (10mM, STEMCELL), Y-27632 (10mM, STEMCELL), A83-01 (500nM, Sigma-Aldrich) and gastrin (10nM, Sigma-Aldrich). The organoid preps were cultured at $37^{\circ} \mathrm{C}$ in $5 \% \mathrm{CO}_{2}$. Butyrate treatment of intestinal or colonic organoids was performed 3 days after the organoids became established in Advanced DMEM/ F12 media. Upon receipt, frozen stocks were generated for the L-WRN cells and were checked for mycoplasma every 3 months. EdU staining of colonic organoids was performed for $16 \mathrm{~h}$ using the Click-iT ${ }^{\circledR}$ EdU Imaging Kit and was developed according to manufacturer's instructions. EdU incorporation was quantified using the program Cellprofiler (http://cellprofiler.org/) comparing EdU area to DAPI stained nuclei per image [37]. Five images per passage of organoids derived from 3 mice per genotype per condition were analyzed.

\section{In vitro tamoxifen induction}

To activate the $\mathrm{Cre}^{\mathrm{ERT} 2}$ transgene in culture, the organoids were incubated with low dose 4-hydroxytamoxifen (4-OH-Tx, 100nM) for $24 \mathrm{~h}$ in complete Advanced DMEM/F12, (Invitrogen). After the incubation, the cultures were washed with PBS and then fresh complete media was added.

\section{Real-time quantitative PCR}

Total RNA from intestine and colon was extracted and purified, using the PureLink RNA Mini Kit (ThermoFisher). RNA $(1 \mu \mathrm{g})$ was DNAse-treated (Promega) and used to generate cDNA using the iScript reverse transcriptase kit (Bio-Rad, Hercules, CA). Realtime quantitative polymerase chain reaction (RT-qPCR) was performed using Platinum Taq DNA polymerase (Invitrogen) on a CFX96 real-time PCR detection system (Bio-RAD), using the following primer sequences $(\mathrm{Tm}=$ $65^{\circ} \mathrm{C}$ for all primers):

Zfp 148: F: 5' TCCAAACCACTGATTCTTCTCTT; R: 5' AGTTCTCTCCCCTCCCCCT

Lgr5: F: 5' TCTTCTAGGAAGCAGAGGCG; R: 5' CAACCTCAGCGTCTTCACCT

Cdkn2: F: GCAGAAGAGCTGCTACGTGA; R: 5' CGTGAACATGTTGTTGAGGC

Cdx2: F: 5' TCTGTGTACACCACCCGGTA; R: 5'

GAAACCTGTGCGAGTGGATG

Reg4: F: 5' GCACAGCTGGGTCTCAAGAT; R: 5'

CATCGAAAGAGGAAGATGGC

Axin2: F: 5' TGCATCTCTCTCTGGAGCTG; R: 5'

ACTGACCGACGATTCCATGT

Notch 1: F: 5' CTGAGGCAAGGATTGGAGTC; R:

5' GAATGGAGGTAGGTGCGAAG

Ctnnb1: F: 5' CAGCTTGAGTAGCCATTGTCC; R: 5' GAGCCGTCAGTGCAGGAG.

\section{Flow cytometry and cell sorting}

Isolated crypts were incubated in culture medium for $45 \mathrm{~min}$ at $37^{\circ} \mathrm{C}$, followed by cell dissociation using 
Accutase (STEMCELL) for $15 \mathrm{~min}$ at $37^{\circ} \mathrm{C}$. Dissociated cells were filtered through a $40 \mu \mathrm{m}$ pore cell strainer (BD Bioscience). TdTomato positive cells were sorted by flow cytometry using an iCyt Synergy Flow sorter (Sony Biotechnology). Single viable epithelial cells from both the intestine and colon were gated by forward scatter, side scatter, pulse-width parameter and by negative staining for DAPI (Sigma Aldrich). Sorted cells were collected in crypt culture medium, embedded in Matrigel and then overlaid with complete culture media.

\section{TUNEL assay}

Three-day old small intestine or colonic organoids were resuspended in cold cell dissociation with $2 \mathrm{mM}$ EDTA/PBS and incubated at $4{ }^{\circ} \mathrm{C}$ for $10 \mathrm{~min}$, and then filtered through a $40 \mu \mathrm{m}$ cell strainer (BD Bioscience). The suspension was centrifuged at $200 \times g$ for 5 min, pelleted and then resuspended in $1 \mathrm{ml}$ of $3.7 \%$ formaldehyde. After incubating for $10 \mathrm{~min}$, the fixed cells were washed in cold PBS and labeled using the TACS 2 TdT fluorescein kit according to manufacturer's procedure (Trevigen, MD). The total number of TdT positive cells for each population was calculated using gating percentage multiplied by total number of cells labeled with DAPI (Sigma Aldrich). Analysis was performed using FlowJo software (TreeStar, Ashland OR).

\section{Senescence-associated galactosidase activity assay}

Galactosidase activity was quantified in intestinal and colonic organoids using the Senescence Cells Histochemical Staining kit (Sigma Aldrich) according to manufacturer's instructions. Staining was developed over 10h and visualized in an inverted optical microscope (Leica). For quantitation, intestinal or colonic organoids were lysed in RIPA buffer (ThermoFisher) for 10min and centrifuged at $10,000 \times \mathrm{g}$ for $5 \mathrm{~min}$, the supernatant was collected and the absorbance was measured on a plate reader at $\mathrm{A}_{460}$.

\section{Chromatin immunoprecipitation (ChIP)}

SW480 cells were treated with $1 \%$ formaldehyde and then quenched with glycine for $5 \mathrm{~min}$ at room temperature. Cell lysates were sonicated to shear DNA into fragments of 200 to $1000 \mathrm{bp}$ ( 8 cycles of 30 second intervals) using a 130W Sonic Vibracell (VCX130PB). An aliquot (5\%) of the lysates was removed and used as the Input, while the remaining solution was used to immunoprecipitate cross-linked protein using a ZBP-89 monoclonal antibody and an IgG antibody as control. Immune complexes were captured using Protein $\mathrm{A} / \mathrm{G}$ agarose beads, after washing, bound proteins were eluted from the beads and diluted 1:15 in deionized water (EZ Magna ChIP A/G kit, Millipore). After proteinase K and RNase A digestions, purified DNA was analyzed by PCR using NovaTap DNA polymerase (Millipore) using flanking promoter primers for $C D K N 2 A$ and primers for chromogranin A (ChrA), a gene not regulated by ZBP89. ChIP-qPCR values were expressed as a percentage of Input DNA.

\section{ChIP-seq}

Mouse STC-1 cells were treated with $2.5 \mathrm{mM}$ butyrate for $6 \mathrm{~h}$ before adding $1 \%$ formaldehyde. After performing chromatin immunoprecipitation (ChIP) with ZBP-89 antibody (Santa Cruz, CA), generation of the library and Illumina sequencing was performed by the UM Sequencing Core. Conversion of the sequences into Fastq was performed using Illumina's CASAVA-1.8.2 software. Q-Scores were determined using ASCII+33. Genomic signatures were analyzed for GC-rich ZBP-89 consensus sites within $1 \mathrm{~kb}$ of the transcriptional start sites (TSS). Duplicate sequencing reads per treatment were aligned to the Mouse GRC $\mathrm{m} 38 / \mathrm{mm} 10$ and BAM files were converted to BigWig for analysis in the UCSC genome browser.

\section{Statistical analysis}

Two-way ANOVA with Tukey's multiple comparisons test was performed to analyze the number of organoids and cell proliferation assays. One-way ANOVA with Kruskal-Wallis multiple comparisons test was used to compare the number of polyps per genotype. Twoway ANOVA with Sidak's multiple comparisons test was used to compare the size of organoids per genotype per condition.

\section{Author contributions}

Conception and design: R. Ocadiz-Ruiz, J.L. Merchant. Development of methodology: R. Ocadiz-Ruiz, A. Photenhauer, L. Ding, J.L. Merchant. Acquisition of data (provided animals, facilities, etc.): R. Ocadiz-Ruiz, A. Photenhauer, M. Hayes, E. Fearon, L. Ding, J.L. Merchant. Writing, review and revision of the manuscript: R. OcadizRuiz, J.L. Merchant. Study supervision: R. Ocadiz-Ruiz, J.L. Merchant.

\section{ACKNOWLEDGMENTS AND FUNDING}

The authors acknowledge support from the Public Health Service Grants: R01 DK55732; UM Cancer Center P30 CA046592; UM Digestive Disease Center 5P30 DK034933. 


\section{CONFLICTS OF INTEREST}

None of the authors have a conflict of interest.

\section{REFERENCES}

1. Merchant JL, Iyer GR, Taylor BR, Kitchen JR, Mortensen ER, Wang Z, Flintoft RJ, Michel JB, Bassel-Duby R. ZBP89, a Kruppel-like zinc finger protein, inhibits epidermal growth factor induction of the gastrin promoter. Mol Cell Biol. 1996; 16:6644-53.

2. Bai L, Merchant JL. Transcription factor ZBP-89 cooperates with histone acetyltransferase p300 during butyrate activation of p21waf1 transcription in human cells. J Biol Chem. 2000; 275:30725-33. https://doi.org/10.1074/jbc. M004249200.

3. Bai L, Merchant JL. ZBP-89 promotes growth arrest through stabilization of p53. Mol Cell Biol. 2001; 21:467083. https://doi.org/10.1128/MCB.21.14.4670-4683.2001.

4. Bai L, Kao JY, Law DJ, Merchant JL. Recruitment of ataxia-telangiectasia mutated to the p21(wafl) promoter by ZBP-89 plays a role in mucosal protection. Gastroenterology. 2006; 131:841-52. https://doi. org/10.1053/j.gastro.2006.06.014.

5. Wieczorek E, Lin Z, Perkins EB, Law DJ, Merchant JL, Zehner ZE. The zinc finger repressor, ZBP-89, binds to the silencer element of the human vimentin gene and complexes with the transcriptional activator, Sp1. J Biol Chem. 2000; 275:12879-88.

6. Feng Y, Wang X, Xu L, Pan H, Zhu S, Liang Q, Huang $\mathrm{B}, \mathrm{Lu}$ J. The transcription factor ZBP-89 suppresses p16 expression through a histone modification mechanism to affect cell senescence. FEBS J. 2009; 276:4197-206. https:// doi.org/10.1111/j.1742-4658.2009.07128.x.

7. Wu Y, Zhang X, Salmon M, Zehner ZE. The zinc finger repressor, ZBP-89, recruits histone deacetylase 1 to repress vimentin gene expression. Genes Cells. 2007; 12:905-18. https://doi.org/10.1111/j.1365-2443.2007.01104.x.

8. Essien BE, Grasberger H, Romain RD, Law DJ, Veniaminova NA, Saqui-Salces M, El-Zaatari M, Tessier A, Hayes MM, Yang AC, Merchant JL. ZBP-89 Regulates Expression of Tryptophan Hydroxylase I and Mucosal Defense Against Salmonella Typhimurium in Mice. Gastroenterology. 2013; 144:1466-77. https://doi. org/10.1053/j.gastro.2013.01.057.

9. Essien BE, Sundaresan S, Ocadiz-Ruiz R, Chavis A, Tsao AC, Tessier AJ, Hayes MM, Photenhauer A, SaquiSalces M, Kang AJ, Shah YM, Gyorffy B, Merchant JL. Transcription Factor ZBP-89 Drives a Feedforward Loop of beta-Catenin Expression in Colorectal Cancer. Cancer Res. 2016; 76:6877-87. https://doi.org/10.1158/0008-5472. CAN-15-3150.

10. Law GL, Itoh H, Law DJ, Mize GJ, Merchant JL, Morris DR. Transcription factor ZBP-89 regulates the activity of the ornithine decarboxylase promoter. J Biol Chem. 1998; 273:19955-64.

11. Li X, Romain RD, Park D, Scadden DT, Merchant JL, Arnaout MA. Stress hematopoiesis is regulated by the Kruppel-like transcription factor ZBP-89. Stem Cells. 2014; 32:791-801. https://doi.org/10.1002/stem.1598.

12. Barker N, van Es JH, Kuipers J, Kujala P, van den Born M, Cozijnsen M, Haegebarth A, Korving J, Begthel H, Peters PJ, Clevers H. Identification of stem cells in small intestine and colon by marker gene Lgr5. Nature. 2007; 449:1003-7. https://doi.org/10.1038/nature06196.

13. Leushacke M, Tan SH, Wong A, Swathi Y, Hajamohideen A, Tan LT, Goh J, Wong E, Denil S, Murakami K, Barker N. Lgr5-expressing chief cells drive epithelial regeneration and cancer in the oxyntic stomach. Nat Cell Biol. 2017; 19:77486. https://doi.org/10.1038/ncb3541.

14. Hinoi T, Akyol A, Theisen BK, Ferguson DO, Greenson JK, Williams BO, Cho KR, Fearon ER. Mouse model of colonic adenoma-carcinoma progression based on somatic Apc inactivation. Cancer Res. 2007; 67:9721-30. https://doi. org/10.1158/0008-5472.can-07-2735.

15. Sasaki N, Sachs N, Wiebrands K, Ellenbroek SI, Fumagalli A, Lyubimova A, Begthel H, van den Born M, van Es JH, Karthaus WR, Li VS, Lopez-Iglesias C, Peters PJ, et al. Reg4+ deep crypt secretory cells function as epithelial niche for Lgr5+ stem cells in colon. Proc Natl Acad Sci U S A. 2016; 113:E5399-407. https://doi.org/10.1073/pnas.1607327113.

16. Verzi MP, Shin H, He HH, Sulahian R, Meyer CA, Montgomery RK, Fleet JC, Brown M, Liu XS, Shivdasani RA. Differentiation-specific histone modifications reveal dynamic chromatin interactions and partners for the intestinal transcription factor CDX2. Dev Cell. 2010; 19:713-26. https://doi.org/10.1016/j.devcel.2010.10.006.

17. Kawasaki Y, Matsumura K, Miyamoto M, Tsuji S, Okuno M, Suda S, Hiyoshi M, Kitayama J, Akiyama T. REG4 is a transcriptional target of GATA6 and is essential for colorectal tumorigenesis. Sci Rep. 2015; 5:14291. https:// doi.org/10.1038/srep14291.

18. Topping DL, Clifton PM. Short-chain fatty acids and human colonic function: roles of resistant starch and nonstarch polysaccharides. Physiol Rev. 2001; 81:1031-64.

19. Verbeke KA, Boobis AR, Chiodini A, Edwards CA, Franck A, Kleerebezem M, Nauta A, Raes J, van Tol EA, Tuohy KM. Towards microbial fermentation metabolites as markers for health benefits of prebiotics. Nutr Res Rev. 2015; 28:42-66. https://doi.org/10.1017/ S0954422415000037.

20. Leontieva OV, Blagosklonny MV. CDK4/6-inhibiting drug substitutes for $\mathrm{p} 21$ and $\mathrm{p} 16$ in senescence: duration of cell cycle arrest and MTOR activity determine geroconversion. Cell Cycle. 2013; 12:3063-9. https://doi.org/10.4161/ cc. 26130 .

21. Dow LE, O'Rourke KP, Simon J, Tschaharganeh DF, van Es JH, Clevers $\mathrm{H}$, Lowe SW. Apc Restoration 
Promotes Cellular Differentiation and Reestablishes Crypt Homeostasis in Colorectal Cancer. Cell. 2015; 161:1539-52. https://doi.org/10.1016/j.cell.2015.05.033.

22. Mathew OP, Ranganna K, Yatsu FM. Butyrate, an HDAC inhibitor, stimulates interplay between different posttranslational modifications of histone $\mathrm{H} 3$ and differently alters G1-specific cell cycle proteins in vascular smooth muscle cells. Biomed Pharmacother. 2010; 64:733-40. https://doi.org/10.1016/j.biopha.2010.09.017.

23. Lorenz V, Hessenkemper W, Rodiger J, Kyrylenko S, Kraft F, Baniahmad A. Sodium butyrate induces cellular senescence in neuroblastoma and prostate cancer cells. Horm Mol Biol Clin Investig. 2011; 7:265-72. https://doi. org/10.1515/HMBCI.2011.020.

24. Vargas JE, Filippi-Chiela EC, Suhre T, Kipper FC, Bonatto D, Lenz G. Inhibition of HDAC increases the senescence induced by natural polyphenols in glioma cells. Biochem Cell Biol. 2014; 92:297-304. https://doi.org/10.1139/ bcb-2014-0022.

25. Nilton A, Sayin VI, Zou ZV, Sayin SI, Bondjers C, Gul N, Agren P, Fogelstrand P, Nilsson O, Bergo MO, Lindahl P. Targeting Zfp148 activates p53 and reduces tumor initiation in the gut. Oncotarget. 2016; 7:56183-92. https://doi. org/10.18632/oncotarget.10899.

26. Puertollano E, Kolida S, Yaqoob P. Biological significance of short-chain fatty acid metabolism by the intestinal microbiome. Curr Opin Clin Nutr Metab Care. 2014; 17:13944. https://doi.org/10.1097/MCO.0000000000000025.

27. Waldecker M, Kautenburger T, Daumann H, Busch C, Schrenk D. Inhibition of histone-deacetylase activity by short-chain fatty acids and some polyphenol metabolites formed in the colon. J Nutr Biochem. 2008; 19:587-93. https://doi.org/10.1016/j.jnutbio.2007.08.002.

28. Lupton JR. Microbial degradation products influence colon cancer risk: the butyrate controversy. J Nutr. 2004; 134:479-82.

29. Bordonaro M, Lazarova DL, Sartorelli AC. Butyrate and Wnt signaling: a possible solution to the puzzle of dietary fiber and colon cancer risk? Cell Cycle. 2008; 7:1178-83.

30. Hamer HM, Jonkers D, Venema K, Vanhoutvin S, Troost FJ, Brummer RJ. Review article: the role of butyrate on colonic function. Aliment Pharmacol Ther. 2008; 27:104-19. https:// doi.org/10.1111/j.1365-2036.2007.03562.x.

31. Donohoe DR, Garge N, Zhang X, Sun W, O'Connell TM, Bunger MK, Bultman SJ. The microbiome and butyrate regulate energy metabolism and autophagy in the mammalian colon. Cell Metab. 2011; 13:517-26. https://doi. org/10.1016/j.cmet.2011.02.018.

32. Donohoe DR, Collins LB, Wali A, Bigler R, Sun W, Bultman SJ. The Warburg effect dictates the mechanism of butyrate-mediated histone acetylation and cell proliferation. Mol Cell. 2012; 48:612-26. https://doi.org/10.1016/j. molcel.2012.08.033.

33. Donohoe DR, Wali A, Brylawski BP, Bultman SJ. Microbial regulation of glucose metabolism and cell-cycle progression in mammalian colonocytes. PLoS One. 2012; 7:e46589. https://doi.org/10.1371/journal.pone.0046589.

34. Zimberlin CD, Lancini C, Sno R, Rosekrans SL, McLean CM, Vlaming H, van den Brink GR, Bots M, Medema JP, Dannenberg JH. HDAC1 and HDAC2 collectively regulate intestinal stem cell homeostasis. FASEB J. 2015; 29:207080. https://doi.org/10.1096/fj.14-257931.

35. Gao XH, Liu QZ, Chang W, Xu XD, Du Y, Han Y, Liu Y, Yu ZQ, Zuo ZG, Xing JJ, Cao G, Fu CG. Expression of ZNF148 in different developing stages of colorectal cancer and its prognostic value: a large Chinese study based on tissue microarray. Cancer. 2013; 119:2212-22. https://doi. org/10.1002/cncr.28052.

36. Madison BB, Dunbar L, Qiao XT, Braunstein K, Braunstein E, Gumucio DL. Cis elements of the villin gene control expression in restricted domains of the vertical (crypt) and horizontal (duodenum, cecum) axes of the intestine. J Biol Chem. 2002; 277:33275-83. https://doi.org/10.1074/jbc. M204935200.

37. Kamentsky L, Jones TR, Fraser A, Bray MA, Logan DJ, Madden KL, Ljosa V, Rueden C, Eliceiri KW, Carpenter AE. Improved structure, function and compatibility for CellProfiler: modular high-throughput image analysis software. Bioinformatics. 2011; 27:1179-80. https://doi. org/10.1093/bioinformatics/btr095. 